\title{
Uncertainty Analysis of Historical Hurricane Data
}

\author{
Lawrence L. Green ${ }^{*}$ \\ NASA Langley Research Center, Hampton, Virginia, 23681
}

\begin{abstract}
An analysis of variance (ANOVA) study was conducted for historical hurricane data dating back to 1851 that was obtained from the U. S. Department of Commerce National Oceanic and Atmospheric Administration (NOAA). The data set was chosen because it is a large, publicly available collection of information, exhibiting great variability which has made the forecasting of future states, from current and previous states, difficult. The availability of substantial, high-fidelity validation data, however, made for an excellent uncertainty assessment study. Several factors (independent variables) were identified from the data set, which could potentially influence the track and intensity of the storms. The values of these factors, along with the values of responses of interest (dependent variables) were extracted from the data base, and provided to a commercial software package for processing via the ANOVA technique. The primary goal of the study was to document the ANOVA modeling uncertainty and predictive errors in making predictions about hurricane location and intensity 24 to 120 hours beyond known conditions, as reported by the data set. A secondary goal was to expose the ANOVA technique to a broader community within NASA. The independent factors considered to have an influence on the hurricane track included the current and starting longitudes and latitudes (measured in degrees), and current and starting maximum sustained wind speeds (measured in knots), and the storm starting date, its current duration from its first appearance, and the current year fraction of each reading, all measured in years. The year fraction and starting date were included in order to attempt to account for long duration cyclic behaviors, such as seasonal weather patterns, and years in which the sea or atmosphere were unusually warm or cold. The effect of short duration weather patterns and ocean conditions could not be examined with the current data set. The responses analyzed were the storm latitude, longitude and intensity, as recorded in the data set, 24 or 120 hours beyond the current state. Several ANOVA modeling schemes were examined. Two forms of validation were used: 1) comparison with official hurricane prediction performance metrics and 2) cases studies conducted on hurricanes from the 2005 season, which were not included within the model construction and ANOVA assessment. In general, the ANOVA technique did not perform as well as the established official prediction performance metrics published by NOAA; still, the technique did remarkably well in this demonstration with a difficult data set and could probably be made to perform better with more knowledge of hurricane development and dynamics applied to the problem. The technique provides a repeatable prediction process that eliminates the need for judgment in the forecast.
\end{abstract}

\section{Nomenclature}

ANOVA = Analysis of Variance

$C D F \quad=$ Cumulative Distribution Function

$L S D=$ Least Significant Difference

NOAA $=$ U. S. Department of Commerce National Oceanic and Atmospheric Administration

$N H C=$ National Hurricane Center

\footnotetext{
* Aerospace Engineer, Space Mission Analysis Branch, Systems Analysis and Concepts Directorate, 1 North Dryden Street, Mail Stop 462, Senior Member of AIAA. 


\section{Introduction}

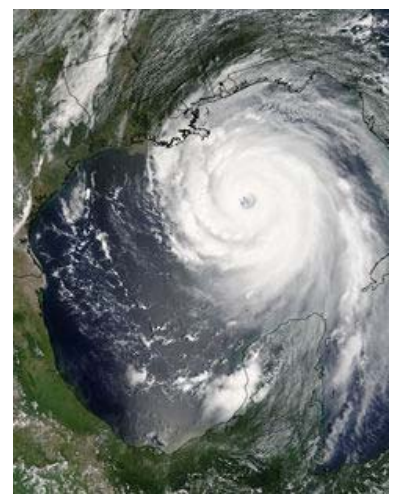

Figure 1. Hurricane Katrina near peak strength on $8 / 28 / 05$.
The devastating effects of tropical storms, especially Hurricane Katrina as shown in Figure 1, during the 2005 hurricane season have been well documented by the news media over the past years. Some of the losses produced by the storm are described on the Wikipedia website (http://en.wikipedia.org/wiki/Hurricane Katrina) in the following quote:

It is possible that Katrina was the largest hurricane of its strength to approach the United States in recorded history; its sheer size caused devastation over 100 miles from the center. The storm surge caused major or catastrophic damage along the coastlines of Louisiana, Mississippi, and Alabama, including the cities of Mobile, Alabama, Biloxi and Gulfport, Mississippi, and Slidell, Louisiana. Levees separating Lake Pontchartrain from New Orleans, Louisiana were breached by the surge, ultimately flooding roughly $80 \%$ of the city and many areas of neighboring parishes. Severe wind damage was reported well inland, and hurricane force wind gusts were reported from Baton Rouge, Louisiana to Dothan, Alabama. Katrina is estimated to be responsible for over $\$ 115$ billion (2005 US dollars) in damages, making it the costliest disaster in U.S. history. The storm has killed at least 1,604 people, making it the deadliest U.S. hurricane since the 1928 Okeechobee Hurricane.

The following list of staggering statistics was made available by the Department of Homeland Security website (http://www.dhs.gov/interweb/assetlibrary/katrina.htm):

- $\quad$ Approximately 90,000 square miles were hit by the storm - roughly the size of Great Britain - directly affecting 1.5 million people. Commercial infrastructure was heavily damaged, with ports - of which one-quarter of all U.S. imports and exports pass through - closed after sustaining damage. Airports, railroads, bridges, warehouses, wharves, offshore facilities, roads, schools and hospitals were also closed after getting hit.

- $\quad$ The Coast Guard rescued 33,000 people -- six times higher than the number of rescues in all of 2004.

- $\quad$ The U.S. Department of Homeland Security's Federal Emergency Management Agency (FEMA) coordinated the rescue of more than 6,500 people and for the first time deployed all 28 of its Urban Search and Rescue teams for a single event.

- $\quad$ Through USDA's various feeding programs and in partnership with many faith-based and community organizations, over 20 million pounds of food were delivered and served to displaced residents, including almost 2 million pounds of baby food.

- $\quad$ Nearly 1.9 million households were signed up to receive close to $\$ 900$ million in USDA food stamps.

- $\quad$ More than 700,000 households have received apartment rental assistance under FEMA's Individuals and Households Assistance Program (\$1.7 billion committed).

- $\quad$ 85,000 households affected by...hurricanes have received temporary lodging through FEMA (\$560 million).

- 180,000 damaged roofs have been covered by the U.S. Army Corps of Engineers under FEMA's "Blue Roof" program, allowing families to remain in their homes as rebuilding occurs.

- $\quad$ Over 10,000 displaced residents were placed in housing across the country primarily near the hurricane region by the USDA, working with U.S. Department of Housing and Urban Development (HUD).

- Nearly $\$ 17.4$ billion has been paid out to National Flood Insurance Program policyholders. 
More than 1.8 million housing inspections have been completed in Alabama, Louisiana, Mississippi and Texas.

For NASA, Hurricane Katrina also produced severe consequences in the forms of lost productivity, damaged facilities, and devastating and demoralizing effects for NASA civil servants and contractors. The following September quote from the U.S. Department of State website (http://usinfo.state.gov/gi/Archive/2005/Sep/12666063.html), following the late August 2005 hurricane, sums up the damage to NASA:

\begin{abstract}
NASA's Stennis Space Center, a sprawling facility on the Mississippi Gulf Coast where space shuttle main engines are tested, and Michoud Assembly Facility, where space shuttle external fuel tanks are manufactured east of New Orleans, are in the stormravaged areas...Facilities at Stennis and Michoud suffered some significant damage but are largely intact. Inspections revealed the potential for only minimal damage to flight hardware. A large number of workers lost their homes; transportation is a problem due to flooded roads and washed-out bridges leading to both facilities. A preliminary estimate indicates damage to NASA facilities and other costs associated with the hurricane could reach $\$ 1.1$ billion, with an estimated $\$ 600$ million in costs at Stennis and $\$ 500$ million at Michoud.
\end{abstract}

Although numerous Space Shuttle launch delays are attributed to the effects of bad weather, relatively few have been due directly to hurricanes, so far, as described in this quote from the article "SHUTTLE SCRUBS - An Analysis of STS Launch Delays, 1981-2000" (http://www.abo.fi/ mlindroo/spacemarkets/STSSCRUB.HTM):

Bad weather is the most common reason why Shuttle launches are delayed (31 scrubs -but only five pre-Challenger -- out of 111, or 28 per cent). However, the launch rarely has to be suspended for more than 1-2 days (the only exception being STS-79 which had to be rolled back into the VAB for protection from Hurricane Fran in October 1996; the delay lasted three weeks).

The Federal Government has already provided NASA an additional \$126 million dollar supplement during FY2005 for hurricane damage that occurred during 2004, and another \$328.4 million dollars that were part of an October 28, 2005 reallocation package for losses incurred during FY2005 by Katrina (The Library of Congress Congressional Research Service November 17, 2005 Report for Congress, http://www.fas.org/sgp/crs/space/RS22063.pdf). So, clearly, NASA has an interest in hurricane prediction.

Analysis of variance (ANOVA) is a statistical technique that subdivides the total variation of a set of data into component parts associated with specific sources of variation ${ }^{1-4}$. The technique is widely used in some fields, most notably in medical and pharmaceutical studies, but has only been applied in engineering studies infrequently, particularly at NASA. For example, a recent search of the NASA Technical Report Server revealed only 323 citations using the words "Analysis of Variance" compared to the almost 1 million citations in the data base dating from about 1964. Other techniques that are used to make hurricane forecasts include: 1) dynamics models which use the physical laws and principles to models the atmospheric dynamic phenomena and numerical models to solve the primitive equations of mass conservation, momentum and energy conservation, 2) statistical models which use classification tools to identify from the history which storms exhibit similar behavior to the current storm and estimate the displacement and/or intensity based on historical information, and 3) dynamical statistical models which are mixtures of the dynamical and statistical models where the outputs from numerical models are used to estimate the atmospheric dynamic conditions of the storm and this atmospheric analysis is input into the statistical model to derive the final prediction ${ }^{5}$. Several 2005 hurricanes are examined using a dynamical statistical model in Ref. 5. Another paper introduces the importance of microphysics in forecasting the track and intensity of a hurricane ${ }^{6}$. Others have looked to potential of improved measurement capabilities ${ }^{7}$ to improve hurricane prediction. Another paper ${ }^{8}$ discusses the potential uncertainty in hurricane track forecasting, which will be discussed more later in this paper. The ANOVA method presented here is one of the statistical techniques, as described in Ref. 5. 
The primary goal of the study was to document the ANOVA modeling uncertainty and predictive errors in making predictions about hurricane location and intensity 24 to 120 hours beyond known conditions, as reported by the data set. A secondary goal was to expose the ANOVA technique to a broader community within NASA. The application of ANOVA to historical hurricane data is, perhaps, an extremely challenging uncertainty analysis problem since the predictability of hurricane tracks and intensity is limited. The U. S. Department of Commerce National Oceanic and Atmospheric Administration (NOAA) website provides measures of the ability of the National Hurricane Center (NHC) to accurately predict the track and intensity of North Atlantic Basin hurricanes. For example, the average error (50\%) for their 48-hour track prediction has steadily decreased from about 300 nautical miles (nm) in 1970 to about $110 \mathrm{~nm}$ in 2004, as shown in Figure 2. Over the same period, the average error for the 48-hour intensity prediction has only decreased slightly, from about 17 knots (kt) in 1970, to about 14 kt currently, as shown in Fig. 3. And, about $5 \%$ of the track and intensity errors for 48 -hour predictions are still of a magnitude of about $300 \mathrm{~nm}$ and $40 \mathrm{kt}$, respectively, as shown in Figures 4 and 5. The 48-hour forecast is often important for emergency managers and preparedness actions and is the only forecast for which a 2009 goal is published, that being the average track error of no more than $125 \mathrm{~nm}$, despite achieved performance slightly better that this goal in 2004 .

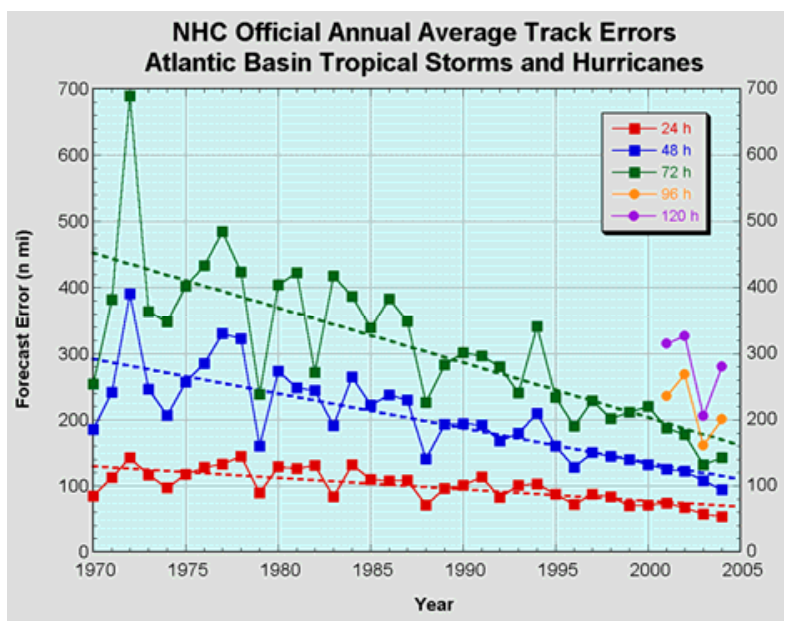

Figure 2. National Hurricane Center Official Annual Average Track Errors.

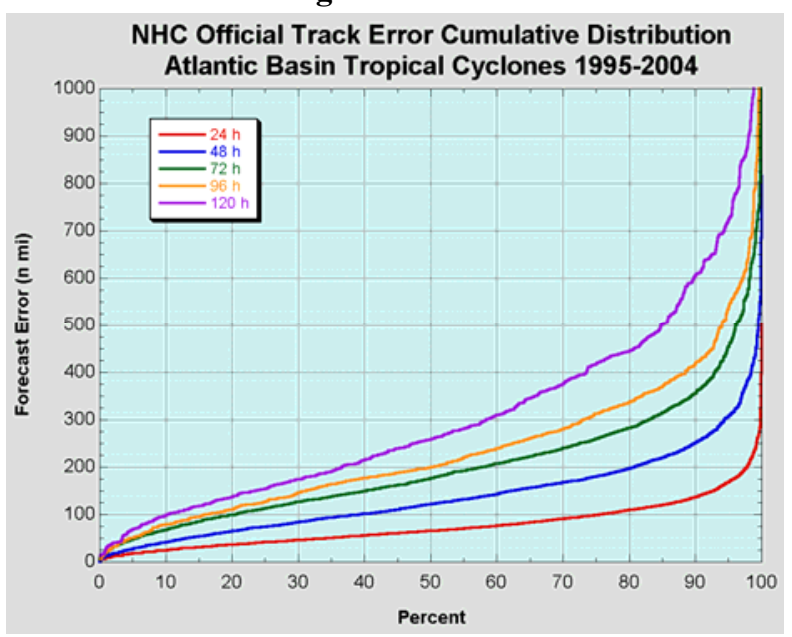

Figure 4. National Hurricane Center Official Track Error Cumulative Distribution Function.

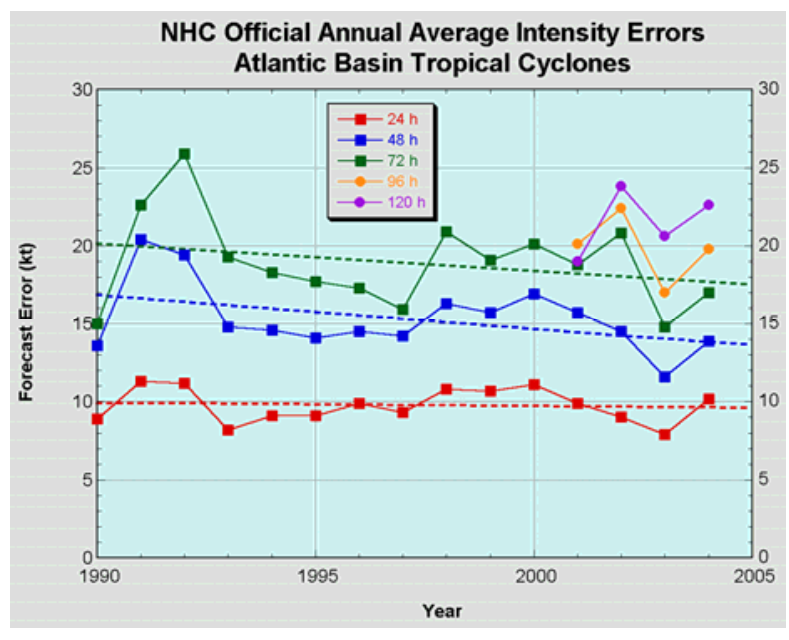

Figure 3. National Hurricane Center Official Annual Average Intensity Errors.

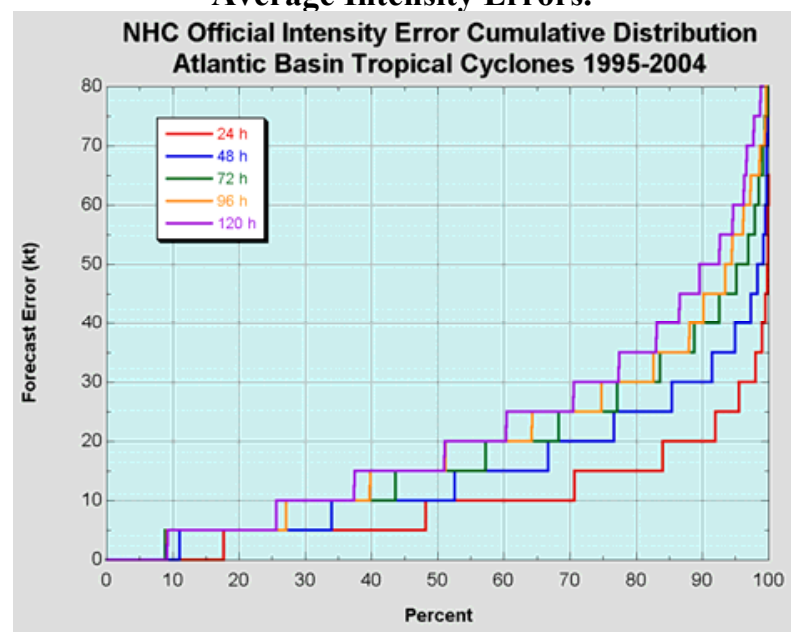

Figure 5. National Hurricane Center Official Intensity Error Cumulative Distribution Function. 


\section{Uncertainty Analysis Method}

The Design-Expert software ${ }^{9-12}$, version 6.0.10, from Stat-Ease, Inc. was used to perform the ANOVA analysis. Hurricane track and intensity data dating from 1851 to the beginning of 2006 were obtained from the NOAA/NHC website http://hurricane.csc.noaa.gov/hurricanes/download.html. The data set included a total of 37234 data points providing track and intensity data for 1353 storms. The data were loaded into Microsoft Excel for pre-processing, which consisted of rearranging the data into a convenient form for use with the Design-Expert software, and performing a few minor calculations, such as creating a time stamp for each entry from the year, month, date and hour entry of each record. From the original data set, 532 storms (39\%) never became hurricanes on the SaffirSimpson Hurricane scale shown in Table 1 during their lifetimes [i.e., the storms did not attain maximum sustained winds in excess of 74 miles per hour $(\mathrm{mph})$ or $64 \mathrm{kt}]$. About $23 \%$ of the storms recorded became Category 1 strength hurricanes during their lifetimes, $16 \%$ became Category 2 hurricanes, $12 \%$ became Category 3 hurricanes, $7 \%$ became Category 4 hurricanes, and only 3\% became Category 5 hurricanes. Those storms which never became hurricanes were excluded from the ANOVA modeling and processing. Also, data from an additional 15 storms that did become hurricanes during calendar year 2005, including four that reached Category 5 status (Emily, Katrina, Rita, and Wilma) were excluded from the ANOVA modeling and processing, in order to serve as the basis of the post-analysis validation studies. Remaining were a total of 26671 recorded measurements, taken at six-hour intervals during the lifetimes of 809 North Atlantic Basin hurricanes dating back to 1851, available for this demonstration. From these measurements, 23490 could be used to make 24-hour predictions, 20368 could be used to make 48 -hour predictions, and only 11958 could be used to make 120-hour predictions. The storms analyzed were not chosen in any particular way and thus included a wide variety of storm tracks, with no apparent common patterns across the entire data set. Sample hurricane track data (as discrete points) are shown in Fig. 6, along with a crude approximation to the eastern seaboard of the United States of America, and the tracks of two particular storms (shown in purple and pink) that will be discussed subsequently. The point coloring in Fig. 6 indicates the month of the year from June through November, and the point size is correlated with the hurricane category, as described in the Saffir-Simpson scale, shown in Table 1.

The factors chosen for this demonstration were: 1) a year fraction computed from the current month, day and hour, divided by the maximum number of days in the year of record - provides a timeline through a typical year to track cyclic behavior on a seasonal basis, 2) the current duration of the storm as measured in six-hour increments as a fraction of a year from its inception, 3) the starting date including the year, month, day of the month and hour provides a timeline through all the records to track cyclic behavior on an annual basis, 4) the starting longitude value, 5) the starting latitude value, 6) the starting maximum wind speed, 7) the current longitude value, 8) the current latitude value, and 9) the current wind speed. The responses for this demonstration were the actual hurricane longitude, latitude and wind speed values ranging from 24 and 120 hours after the input record.

Data typical for each storm is shown in Table 2, in this case, the track and intensity of Hurricane Emily (July 2005). Table 2 shows the reading number of the storm, the date and time in universal time or hours Zulu (Greenwich Mean Time), the longitude and latitude (in degrees) and maximum sustained wind speed (in knots) of the hurricane, all as functions of time. Also shown are the longitude 24 and 48 hours after the current reading, i.e., the first number in column seven is the fifth number of column four; the first number of column eight is the ninth number in column four. The specific use of these future states is discussed subsequently.

Three types of uncertainty studies were conducted: 1) one temporal factor (the current longitude, latitude, or wind speed) was used to predict a similar response 24 to 120 hours in advance, 2) two or more temporal factors of the same type (the current and some previous longitudes, latitudes, or wind speeds) were used to predict a similar response 24 to 120 hours in advance, and 3) multiple factors at a given time were used together to predict each of the three responses 24 to 120 hours in advance. The data from Table 2 is used to illustrate these three types of studies. In the first analysis type, for example, longitude data (column 4) from Readings 1 through 38 are used to predict the longitude data (column 7) for Readings 1 through 38, respectively (24-hour predictions). In the second type of analysis, for example, longitude data from Readings 1 through 34 of columns 4 and 7 are used together to predict the data in column 8 (24-hour predictions using storm history data). Although other variants are possible, this second type of analysis will only be shown for data at 24-hour increments, as described, since that is the way the data has been arranged for the other studies. The third type of analysis could use together the longitude, latitude, and wind 
speed data (columns 4, 5 and 6) from Readings 1 through 38 are used together to independently predict, for example, the longitude data of column 7 (24-hour predictions).

In a matter of seconds, a numerical model of user-specified order (linear, 2-factor interference, quadratic, or cubic) was calculated to fit the input data. The model is a polynomial fit to the input data (responses as functions of the factors) using a regression process. Design-Expert computes $95 \%$ confidence intervals for each coefficient in the polynomial, i.e., each coefficient is given terms of a nominal value, as well as upper and lower bounds which represent the range in which the coefficient is expected to lie with $95 \%$ confidence. Because the model is a "best fit" to the input data, it does not necessarily pass through all the input data points. The model is then evaluated at all the input conditions, and residuals (differences between the model value at a given input set and the actual response value for the same input set) are produced at each of the input conditions. A statistical analysis of the model and the distribution of the model output values across all of the input sets are also computed. The software also provides a collection of graphical diagnostics which help the user to evaluate the suitability of the input data set for use within the ANOVA process and which examine the behavior of the resultant computed data, suggesting transformations which should be applied to the data to potentially reduce the modeling uncertainty and/or predictive errors. Postanalysis validation studies were also conducted, in which a model generated from selected input data sets was used to predict the behavior of other hurricanes not included in the modeling and ANOVA.

For the purposes of this paper, the term "model uncertainty" is used to refer to that range of possible polynomials described by the $95 \%$ confidence intervals of each polynomial coefficient. The term "predictive error" is used to refer to the difference between a model value at some input set and the actual response value for the same input set; this term includes both predictions for the data used to construct the model, as well as predictions for validation data sets that were not used to construct the model. In all cases, the data was used in a predictive sense to determine, as though the storms were progressing and data were being measured in real time, if the ANOVA method could provide useful 24- to 120-hour predictions of the storm track and intensity. Another way to use the data would be to analyze the data in reverse, to see if the ANOVA method can determine starting or early development hurricane characteristics of particularly strong or devastating storms such as Katrina. The goal of such a study would be to identify starting or early development characteristics of storms likely to develop into very strong or devastating hurricanes, in order to increase the potential time available to perform evacuations or preventive ground operations for the Space Shuttle or other NASA programs. This technique was not demonstrated for this paper, but a technique which examines the predictability of storms from their onset conditions is discussed.

Figure 7, includes track data for hurricanes, tropical storms and tropical depressions, all of which are tracked by NOAA/NHC, as well as 50,100, and 200 mile radius circles (the bulls-eye in the upper left-hand corner) centered at Hampton, VA, the site of NASA Langley Research Center. It should be clear from Figures 6 and 7 that it would be difficult to define a "typical" storm path or progression; some storms form in the Gulf of Mexico, some in Caribbean, some near the west coast of Africa; some storms form near 10 degrees latitude, while other form at 20 degrees latitude or more. Many storms progress from east to west, trending across the Atlantic Ocean toward the United States or North America, but a significant number do not follow this pattern and may even circle or go the opposite direction. Again, no attempt was made to select well behaving storms in this demonstration, but unreported limited research in eliminating troublesome storms from consideration did improve the prediction errors. Returning to Figure 6, the path of Tropical Storm Josephine (Oct. 1996) is highlighted in purple with large connected circular symbols; the storm formed near the western edge of the Gulf of Mexico and moved steadily to the Northeast, and happened to pass very close to Hampton, VA. This storm had the western-most starting point of the storms analyzed. Also highlighted in Figure 6 in pink with large connected square symbols is the path of Hurricane Lili (Dec. 1984), which formed in the mid North Atlantic, moved South and East, circled back to the North, then finally moved to the South and West. These two storms are about as atypical as possible, compared to the rest of the storm tracks considered, but are certainly representative of the diversity of storms that may occur, and hence, must be considered within a statistical analysis. 


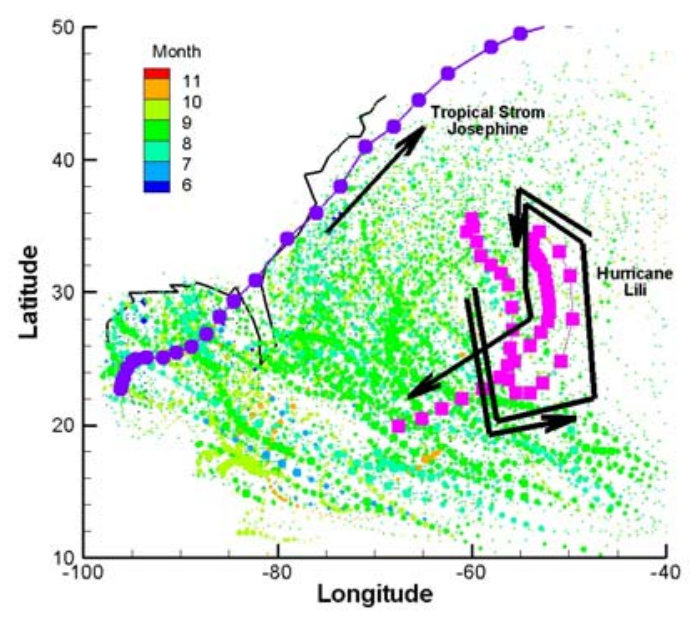

Figure 6. North Atlantic Basin Hurricanes, Sized by the Saffir-Simpson Hurricane Scale.

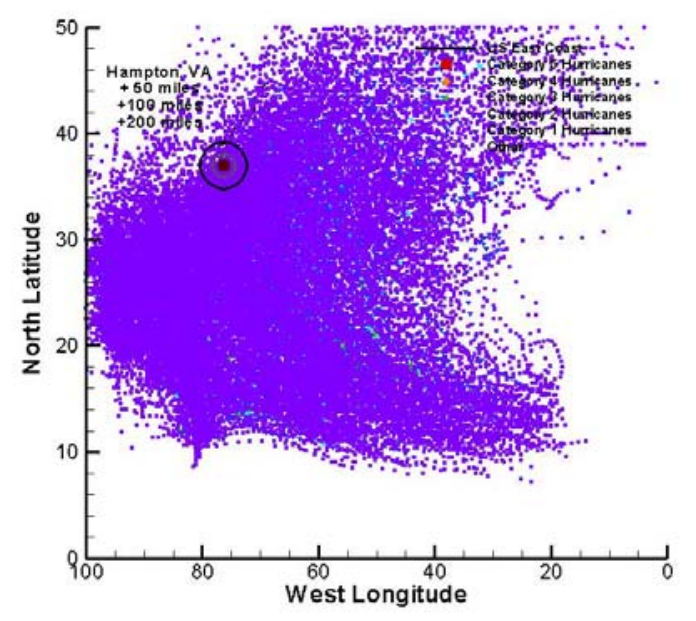

Figure 7. North Atlantic Basin Hurricanes and Tropical Storms, with Hampton, VA.

The NOAA/NHC hurricane forecast verification procedure is described in detail in numerous web pages beginning at http://www.nhc.noaa.gov/verification/verify2.shtml. In particular, Figures 2-5 were all presented there and discussed. As mentioned previously, the stated goal of the $\mathrm{NHC}$ is an average 48-hour track forecast prediction error of no more than $125 \mathrm{~nm}$, to be achieved by 2009 . Their achieved average 48-hour track forecast prediction error was just $107 \mathrm{~nm}$ in 2003, better that the stated goal. The achieved accuracy of 2003 is unusually good, not representative of their anticipated accuracy.

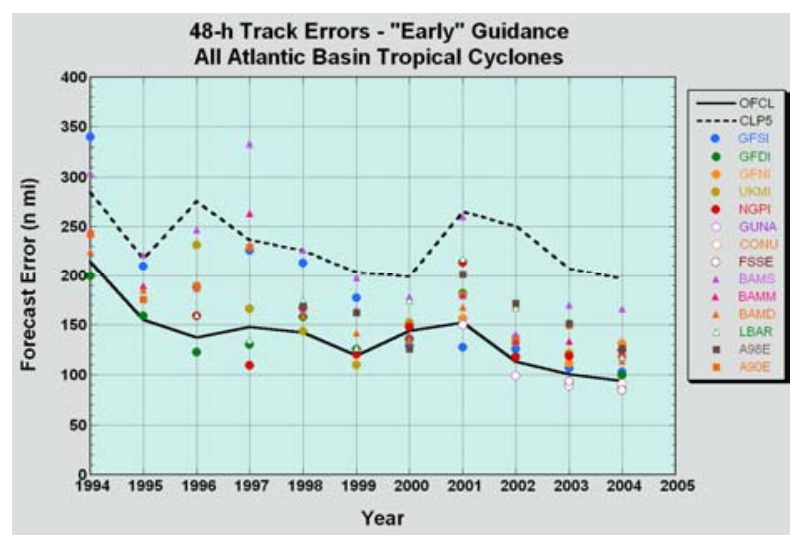

Figure 8. A homogeneous selection of NHC

"early" models annual average model track errors for the period 1994-2004 with NHC official and CLIPER5 model errors shown for comparison.
The official forecasting process of the NHC draws upon many computational models, analyst expertise and perhaps, even, intuition. As shown in Figure 8, at least 14 different models are currently available for predictions early in the lifetime of a storm. The 48-hour annual average $(50 \%)$ forecast error of these various models (symbols) from 1994 through 2004 is compared with the average official forecast error (black solid line), and the average forecast error from the statistical CLIPER5 model (black dashed line) dating from 1972. It can be seen that the average 48-hour modeling forecast error in 2004 varied from about $160 \mathrm{~nm}$ to about $90 \mathrm{~nm}$, with the official 48-hour forecast error at about $95 \mathrm{~nm}$. Ref. 8 described the 48 -hour track prediction uncertainty as about $122-145 \mathrm{~nm}$, and indicates that circular areas, drawn around the official forecasts, with static radii based on NHC's official forecast error for the last ten years of $150 \mathrm{~nm}$ at 48 hours, contained the verifying

Tropical Cyclone position $67-71 \%$ of the time ${ }^{8}$. Increasing the radius to $250 \mathrm{~nm}$ at 48 hours, the circular area contained the verifying Tropical Cyclone position $73-76 \%$ of the time ${ }^{8}$. The official NHC modeling errors will be compared with current results later in this paper. The term "average" as used by the NHC with respect to model uncertainties and forecast errors shown in Figures 2-5 and 8 is simply the 50\% point on the specific hour prediction as shown on a CDF such as in Fig. 4, where half of all the predictions made exceed this value, some by a great extent. 


\section{Results}

For simplicity, the ANOVA analysis and prediction technique will first be demonstrated for a tiny subset of all the data available, namely the track and intensity data for Hurricane Emily (July 2005) given in Table 2. This storm was chosen for the initial illustration for several reasons:

1) it was the first of four Category 5 hurricanes (Emily, Katrina, Rita, and Wilma) from the 2005 season, as shown in Figure 9 along with a crude representation of the eastern seaboard of the United States

2) it was one of only 72 hurricanes since 1851 , and the only hurricane from 2005 , that moved monotonically from the Southeast of the Atlantic Ocean to the Northwest and toward North America which should minimize prediction errors

3) the author happened to be vacationing on Grand Cayman Island, the tiny spec in the Caribbean Sea of Fig. 9, at the time Hurricane Emily was moving through the region.

Figure 10 shows an image representative of what could be observed during television coverage while Hurricane Emily approached Grand Cayman Island (center of the red circle). An online article from Sun-Sentinel (http://www.sun-sentinel.com/news/weather/weblog/hurricane/archives/2005/07/index.html) provided the image shown in Figure 11, and discussed the official modeling of Hurricane Emily:

Up until now, the computer models have been remarkably consistent in their predictions for Tropical Storm Emily. However, in the last few hours the UKMET model has shifted radically northward (the UKMET is the orange line on the attached map, Figure 11).

The models often disagree, so the National Hurricane Center isn't attaching much significance to the change. But it is interesting, especially to the paranoid among us.

The grid in Figure 11 represents five degree blocks of latitude and longitude. Thus, the track prediction variability shown in Fig. 11 is about 10 to 15 degrees longitude at constant latitude, or about 5 to 7 degrees of latitude at a constant longitude. A more detailed discussion of the official track and intensity models used for hurricane forecasting can be found at http://www.nhc.noaa.gov/modelsummary.shtml. Up to nine factors were chosen, or created, from the data available (illustrated in Table 2) that could potentially influence the track and intensity of hurricanes as they develop and progress. However, no information was available within this data set regarding local atmospheric or water temperatures, or short duration weather patterns which would logically be expected to influence the storm development and path. The demonstration will then be expanded to the full data set described previously. Finally, validation studies will be described for the four Category 5 hurricanes from calendar year 2005.

Figure 12 shows a plot generated by the Design-Expert software for the Hurricane Emily data taken from Table 2, where the longitude at 24 hours after a given input point is to be predicted as a function only of the current longitude (one independent variable set, one dependent variable set). The normal probability plot indicates whether the studentized residuals (prediction error determined as a difference between the actual measurement and the model prediction, divided by the standard deviation of the residuals) follow a normal distribution, in which case the points will follow the straight line. The software warns to expect some scatter even with normal data, and to look for definite patterns like an "S-shaped" curve, which indicates that a transformation of the response may provide a better analysis. In this case, the data points follow the straight line quite well indicating a normal distribution which departs from a straight line behavior at about $10 \%$ and $95 \%$ probability. Figure 12 is interpreted to mean that most of the data analyzed for this storm can be reasonably considered to be normally distributed about a mean. This assumption is not necessary for the analysis to be conducted, but is an underlying assumption of the ANOVA technique and simplifies discussion of the results. An additional assumption of the ANOVA technique is that of constant variance. For cases such as this, with very few data points, the assumptions of normality and constant variance may not be strictly true, but the validity of the assumptions generally increases substantially as more data points are considered.

Figure 13 provides a guideline for selecting the correct power law or logarithmic transformation to be applied to the input responses. A recommended transformation may be listed, based on the best lambda value, which is found at the minimum point of the curve generated by the natural $\log$ of the sum of squares of the residuals. If the $95 \%$ 
confidence interval (Low and High C.I. on the figure) around this lambda includes 1, as in the case shown, then the software does not recommend a specific transformation. In this case, the software has recommended that a square root transformation with additive constant $(\mathrm{k}=110.55)$ be applied to input responses. The affect of applying this transformation will be discussed subsequently.

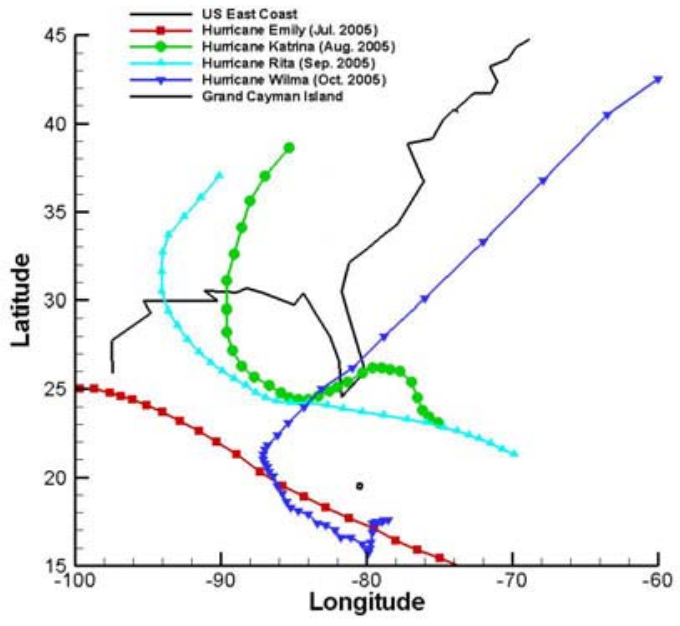

Figure 9. Category 5 hurricanes from 2005.

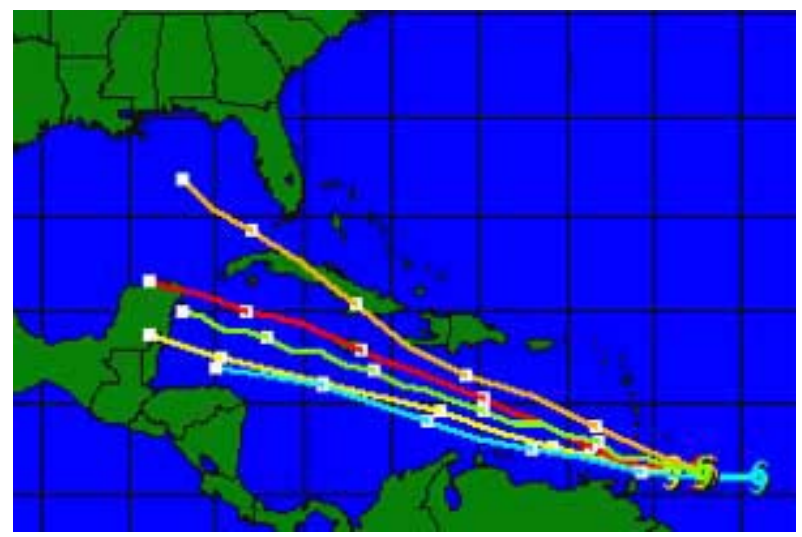

Figure 11. Variation Among Official Track Prediction Models for Hurricane Emily.

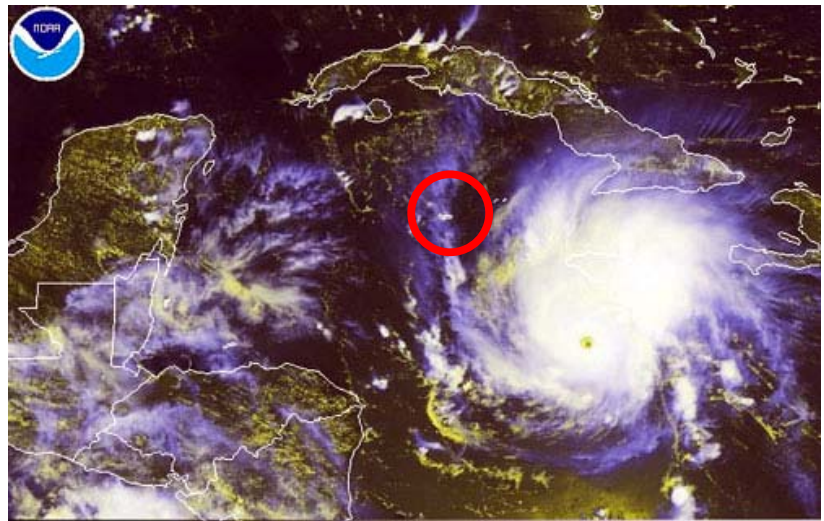

Figure 10. Hurricane Emily approaching Grand Cayman Island.

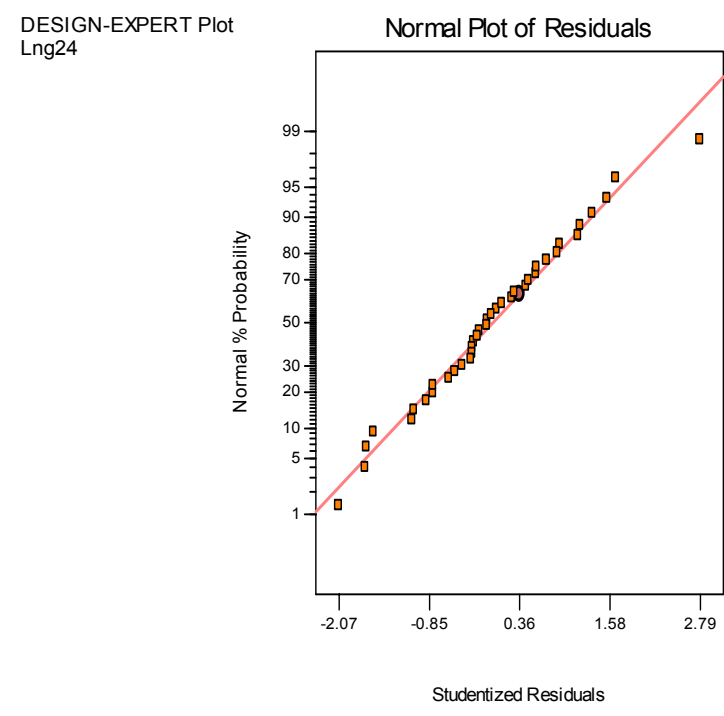

Figure 12. Design-Expert plot of Studentized Residuals vs. the Run Number. 


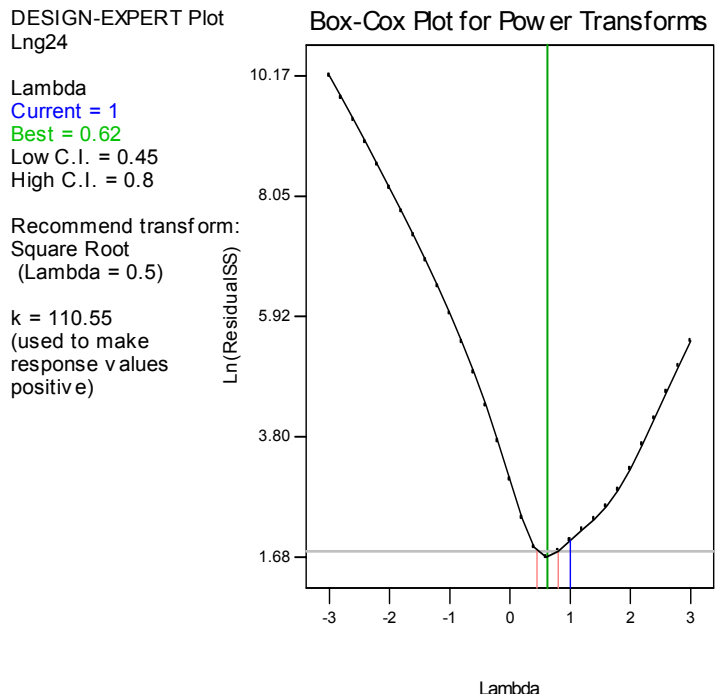

Figure 13. Design-Expert Box-Cox plot For Power Transformations.

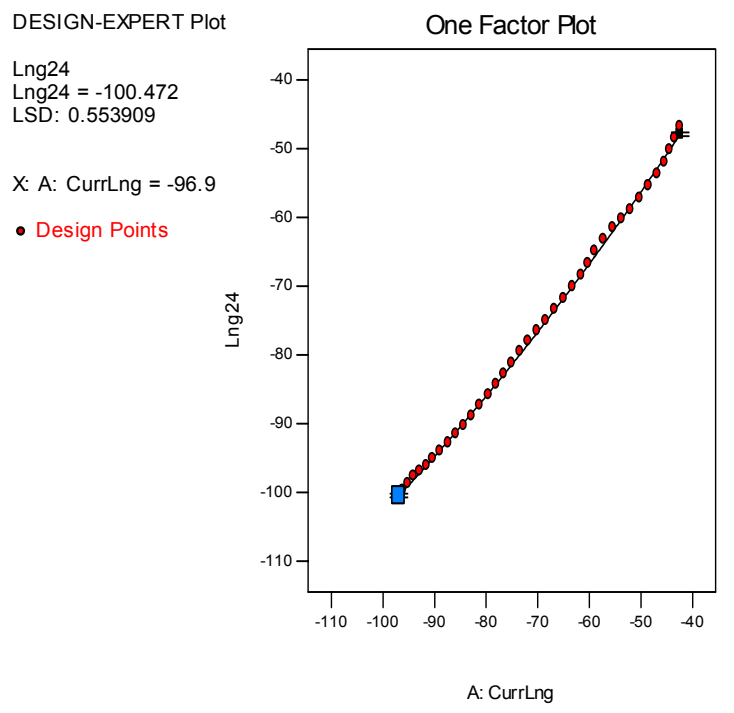

Figure 14. Design-Expert One-Factor plot Showing Lng+24 as a function of CurrLng.

Figure 14 illustrates the Design-Expert prediction model (solid line) and actual input data responses (circles) used to construct the model. In this case, the software generated the curve by fitting a quadratic to the input data. The independent variable for the cubic curve at each point was the current longitude (CurrLng), and the dependent variable at each point was the longitude at 24 hours beyond the current longitude (Lng+24). For response, the terms like Lng24 and Lng+24 are use interchangeably, specifically the former is used in the summary tables. The error bar at the upper right-hand corner of the plot is the $95 \%$ least significant difference (LSD) bar, which indicates the smallest resolvable differences in the functional values given just the information from the input data sets. An error bar of exactly the same size is also present at the lower-left hand corner of the plot, but has been highlighted with the mouse (blue square) to reveal its value of 0.554492 degrees of longitude at the CurrLng value of -96.9 degrees longitude, and predicted response value Lng+24 of -100.472; the actual response value at this point had a value of -100.5 degrees longitude. The LSD should be considered the $95 \%$ confidence measure of the mean model uncertainty. In addition, as the model does not perfectly replicate all of the input design points, so a prediction error must be considered.

At this point, it is necessary to make a digression to discuss how the accuracy of the results in this paper will be presented, and how modeling uncertainties and/or prediction errors in longitude are handled. In order to compare results from this paper to the $\mathrm{NHC}$ official hurricane forecasts, the results must first be presented in comparable units. The NHC track forecasts have accuracy described in nautical miles, as shown in Figs. 2 and 4. In Fig. 4, the forecast error is presented as a cumulative distribution function (CDF). Thus, it is expected, for example, that $50 \%$ of the 96-hour storm track forecast errors (orange curve) will be less than or equal $200 \mathrm{~nm}$. Similarly, it is expected that $95 \%$ of the 96 -hour storm track forecast errors will be less than or equal about $550 \mathrm{~nm}$. These bounds include all forecasts made, for all storms at all longitudes and latitudes. Therefore, Design-Expert track errors given in degrees longitude and degrees latitude must be converted to nautical miles from the correct storm locations.

From the global convention of defining longitude and latitude, it should be obvious that an error in degrees of longitude translates into a nonlinear function in miles (or nautical miles) depending upon the degrees latitude at which the error is assessed. For the calculations in this paper, the Earth is assumed to be perfectly spherical with a radius of 4000 miles (3476 nautical miles, 1 mile $=0.868976 \mathrm{~nm}$ ). Thus, the circumference of the Earth at zero latitude is about 25133 miles or about $21840 \mathrm{~nm}$. At latitude of 30 degrees, a circle drawn around the earth of constant latitude has a circumference of 21766 miles $(18914 \mathrm{~nm})$. The radius of such a circle is proportional to the cosine of the latitude angle. Thus, an error or uncertainty of one degree of longitude is about 70 miles $(61 \mathrm{~nm})$ at the equator, and about 60 miles $(53 \mathrm{~nm})$ at 30 degrees of latitude. An error or uncertainty of one degree of latitude is 
always equal to about 70 miles $(61 \mathrm{~nm})$. The modeling uncertainty and the prediction error in degrees of longitude and latitude must be combined to determine a total uncertainty or error in $\mathrm{nm}$. For individual forecast points, it is a simple matter to compute the correct longitude uncertainty or error associated with a given prediction latitude. However, because the model development is associated with many storms that each move over a different range of longitude and latitude during its lifetime, (in general, all the hurricanes recorded from 1851 to 2004) it is unclear how to correct for longitude uncertainty or error. Since the bulk of the eastern seaboard of the United States lies between 25 and 45 degrees north latitude (as shown in Figure 2, the northern shore of the Gulf of Mexico is at about 30 degrees longitude), longitude corrections will only be shown at 30 degrees latitude unless otherwise noted. The NHC also reports wind speed forecast errors in knots (nm/hour), so that from Table 1, a Category 1 hurricane ranges in wind speed from about 74 miles per hour (64 knots) to about 95 miles per hour ( 83 knots).

Returning to the example above, it is instructive to examine a piece of the ANOVA output from Design-Expert, as shown in Figure 15. Line 1 simply identifies the response being analyzed, in this case, Lng+24, the longitude 24 hours after the input longitude. Line 2 indicates the order of polynomial that was fitted to the input data using regression methods, here a quadratic. Lines 4 through 10 provide information about the model terms estimating factor effects and the residual (prediction error). Specifically, (quoting again from the Design-Expert Help screens) the Sum of Squares (SS) is the total of the sum of squares for the terms in the model, as reported on the Model screen for a response surface method, such as this example. The Degrees of Freedom (DF) for the model is the number of model terms, including the intercept, minus one. The Mean Square (MS) is an estimate of the model variance, calculated by the model sum of squares, divided by model degrees of freedom. The F Value shows the test for comparing model variance with residual (error) variance. If the variances are close to the same, the ratio will be close to one and it is less likely that any of the factors have a significant effect on the response. The F Value is calculated by Model Mean Square divided by Residual Mean Square. The Prob > F is Probability of seeing the observed F value if the null hypothesis is true (i.e., there is no factor effect and the F Value is obtained purely by chance). Small probability values call for rejection of the null hypothesis. The probability equals the proportion of the area under the curve of the F-distribution that lies beyond the observed $\mathrm{F}$ value. The F distribution itself is determined by the degrees of freedom associated with the variances being compared. In "plain English", if the Prob $>F$ value is very small (less than 0.05 ) then the terms in the model have a significant effect on the response.

Lines 12 through 15 give a collection of summary statistics for the model. The Std Dev: (standard deviation or Root Mean Square Error, MSE) is the square root of the residual mean square described above, which is essentially an estimate of the standard deviation associated with the experiment. The Mean is the overall average of all the response data. The C.V. is Coefficient of Variation, i.e., the standard deviation expressed as a percentage of the mean, which is calculated by dividing the Std Dev by the Mean and multiplying by 100 . The PRESS is Predicted Residual Error Sum of Squares, which is a measure of how the model fits each point in the design. The PRESS is computed by first predicting where each point should be from a model that contains all other points except the one in question. The squared residuals (difference between actual and predicted values) are then summed. The RSquared is a measure of the amount of variation around the mean explained by the model. The adjusted R-squared (Adj R-Squared) is a measure of the amount of variation around the mean explained by the model, adjusted for the number of terms in the model; it decreases as the number of terms in the model increases, if those additional terms don't add value to the model. The predicted r-squared (Pred R-squared) is a measure of the amount of variation in new data explained by the model. When the predicted r-squared and the adjusted r-squared differ by more than 0.20 , the user should look for outliers, consider transformations, or consider a different order polynomial to reduce the model uncertainty and/or predictive errors associated with the model. Adequate Precision (Adeq Precision) is a signal-to-noise ratio; values greater than 4 indicate adequate model discrimination.

A Factor is one of the experimental variables selected for inclusion in the predictive model. Lines 17-21 provide statistics for each of the factors currently in the model, in coded form. The coded form variables are a scaling of the independent variable values, produced by the software, to allow the calculations to be performed independent of the units for each factor; these always range from -1 to +1 for each factor in the model. The Coefficient Estimate is the regression coefficient representing the expected change in a response per unit change in a specific Factor when all remaining factors are held constant. The DF is the Degrees of Freedom for the term, equal to one for testing coefficients. The Standard Error is the standard deviation associated with the coefficient estimate. The 95\% Confidence Intervals (CI) High and Low represent the range that the true coefficient should be found in $95 \%$ of the time. If this range spans 0 (one limit is positive and the other negative) then the coefficient of 0 could be true, indicating the factor has no effect. The Variance Inflation Factor (VIF) measures how much the variance of the 
model is inflated by the lack of orthogonality in the design. For orthogonal factors, the VIF is one; VIF $>10$ indicates that the factors are too correlated to be treated as independent. The term "A-CurrLng" in line 20 is a combination of Design-Expert's notation for factors $(A, B, C, \ldots)$ and the user's name for the factor, in this case, the current longitude of a hurricane (CurrLng). Similarly, A2 in lines 21 and 28 is simply the value of A squared; CurrLng2 in line 35 is simply the value of CurrLng squared. Lines 25-28 represent the quadratic model in coded form; lines 32-35 represent the quadratic model in actual variable values.

\begin{tabular}{|c|c|c|c|c|c|c|c|}
\hline Line & ANOVA & & & & & & \\
\hline Number & Output & & & & & & \\
\hline 1 & Response: & Lng+24 & & & & & \\
\hline 2 & ANOVA for & Response Sur & ace $\mathrm{C}$ & Model & & & \\
\hline 3 & Analysis of & ariance table & Partia & f squares] & & & \\
\hline 4 & & Sum of & & Mean & $\mathrm{F}$ & & \\
\hline 5 & Source & Squares & DF & Square & Value & Prob > F & \\
\hline 6 & Model & 10309.994 & 2 & 5154.9971 & 25042.75 & $<0.0001$ & significant \\
\hline 7 & A & 10307.179 & 1 & 10307.179 & 50071.824 & $<0.0001$ & \\
\hline 8 & $\mathrm{~A} 2$ & 18.828866 & 1 & 18.828866 & 91.469803 & $<0.0001$ & \\
\hline 9 & Residual & 7.2046761 & 35 & 0.2058479 & & & \\
\hline 10 & Cor Total & 10317.199 & 37 & & & & \\
\hline 11 & & & & & & & \\
\hline 12 & Std. Dev. & $\begin{array}{l}0.4537046 \\
-\end{array}$ & & $\begin{array}{l}\text { R-Squared } \\
\text { Adj R- }\end{array}$ & 0.9993017 & & \\
\hline 13 & Mean & 76.194737 & & $\begin{array}{l}\text { Squared } \\
\text { Pred R- }\end{array}$ & 0.9992618 & & \\
\hline 14 & C.V. & -0.595454 & & $\begin{array}{l}\text { Squared } \\
\text { Adeq }\end{array}$ & 0.9991306 & & \\
\hline 15 & PRESS & 8.9697562 & & Precision & 412.0728 & & \\
\hline 16 & & & & & & & \\
\hline 17 & & Coefficient & & Standard & $95 \% \mathrm{Cl}$ & $95 \% \mathrm{Cl}$ & \\
\hline 18 & Factor & Estimate & DF & Error & Low & High & VIF \\
\hline 19 & Intercept & 76.324323 & 1 & 0.1141498 & -76.55606 & 76.092587 & \\
\hline 20 & A-CurrLng & 26.265519 & 1 & 0.1173787 & 26.027228 & 26.503811 & 1.000688 \\
\hline 21 & $\mathrm{~A} 2$ & 2.1177315 & 1 & 0.2214277 & 1.6682093 & 2.5672537 & 1.000688 \\
\hline 22 & & & & & & & \\
\hline 23 & Final Equati & n in Terms o & Code & & & & \\
\hline 24 & & & & & & & \\
\hline 25 & & Lng+24 & $=$ & & & & \\
\hline 26 & & 76.324323 & & & & & \\
\hline 27 & & 26.265519 & ${ }^{*} \mathrm{~A}$ & & & & \\
\hline 28 & & 2.1177315 & ${ }^{*} \mathrm{~A} 2$ & & & & \\
\hline 29 & & & & & & & \\
\hline 30 & Final Equati & n in Terms o & Actua & & & & \\
\hline 31 & & & & & & & \\
\hline 32 & & Lng+24 & $=$ & & & & \\
\hline 33 & & 4.6444104 & & & & & \\
\hline 34 & & 1.3611452 & ${ }_{*}^{*} \mathrm{Cu}$ & & & & \\
\hline 35 & & 0.0028519 & Curr & & & & \\
\hline
\end{tabular}

12

American Institute of Aeronautics and Astronautics 
Lines 23-28 show the predictive model equation in coded form. It is convenient to consider the model uncertainty at the average input location, since this point is near most of the input data, and hence is representative of the design space. Moreover, since all the terms in the model, except the intercept, will be multiplied by products of the input factors always equal to zero in coded terms, they contribute nothing to the model uncertainty independent of the model chosen, or the number of factors. The one-sided $95 \%$ model uncertainty is simply the difference between the High 95\% CI and the mean value, for the Intercept, translated to appropriate units.

Here, the $95 \%$ CI difference is about 0.463 degrees longitude, so the one-sided $95 \%$ model uncertainty is about 0.232 degrees longitude, i.e., 14 miles or $12 \mathrm{~nm}(1 \mathrm{mile}=0.868976 \mathrm{~nm})$, when evaluated at 30 degrees longitude, as described above. This convention will be used to report the one-sided model uncertainty as simply the difference between the 95\% CI High minus the Coefficient Estimate, for the intercept, converted to appropriate units. The value of the $\mathrm{LSD}=0.554492$ degrees of longitude could alternatively be used to evaluate the model uncertainty (half above the mean value, and half below the mean value, here providing a one-sided uncertainty bound of $15 \mathrm{~nm}$ ). This is proportional to the intercept uncertainty method, but has three distinct disadvantages relative to using the model intercept uncertainty described above: 1) the calculation of the LSD involves matrix operations, compared to a scalar calculation above, and 2) the calculation of the LSD is only performed by the software at the bounds of the domain of interest, possibly far away from many of the input points, with the consequent loss of accuracy relative to an average point, and 3) the LSD calculation has an intermittent, known bug in version 6 of the Design-Expert software which was acknowledged by a company statistician after the author contacted them with specific question regarding the LSD calculation; the bug allows the LSD to be calculated inconsistently in certain situations, depending on the state of the computer memory, and has reported been fixed in version 7 of the software.

The predictive error will also be evaluated so as to bound the mean of a normal distribution by $50 \%$ and $95 \%$, using the mean and standard deviation reported in lines 12 and 13 of Fig. 15. Specifically, the one-sided $50 \%$ predictive error will be computed using the Excel function NORMINV(0.75, Mean Value, Std Dev) $=\operatorname{NORMINV}(0.75$,$76.195,0.454)=-75.88$ degrees longitude; the change from the mean value is 0.440 degrees longitude, or $16 \mathrm{~nm}$, evaluated at 30 degrees latitude, as described above. Similarly, the $95 \%$ predictive error will be computed using the Excel function NORMINV(0.975,Mean Value, Std Dev) $=\operatorname{NORMINV}(0.975,-76.195,0.454)=-75.30$ degrees longitude; the change from the mean value is 1.02 degrees longitude, or $47 \mathrm{~nm}$, evaluated at 30 degrees latitude, as described above. These procedures provide clear, simple, repeatable, representative, and consistent means to evaluate both the model uncertainty and the prediction error across many diverse cases.

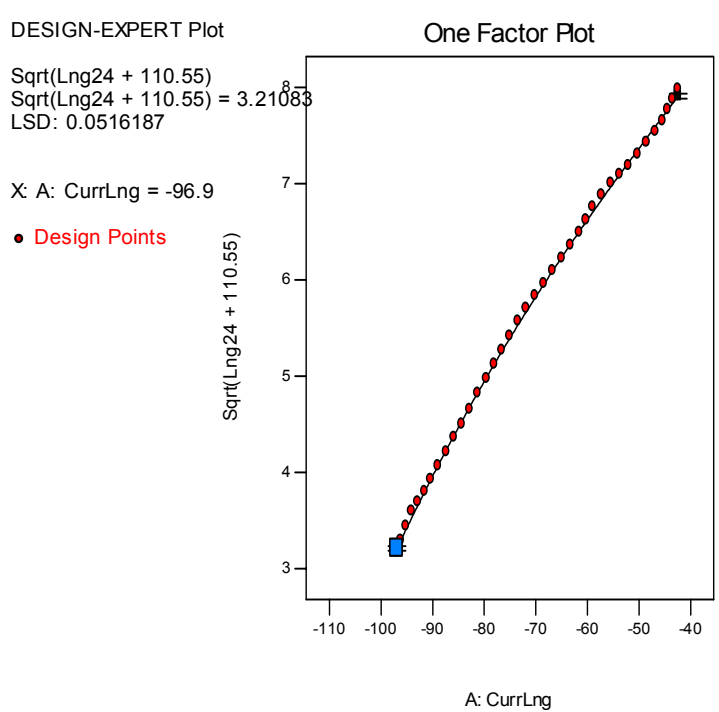

Figure 16. Design-Expert One-Factor plot Showing Lng+24 as a function of CurrLng.
The use of transformations suggested by the software to ensure the assumption of constant variance (here to use a square root transformation with additive constant of $110.55)$ is also henceforth dispensed with, because the practice makes comparisons with the reference NHC forecast goals less clear and frequently does not noticeably change the conclusions drawn from the results. Figure 16 illustrates the Design-Expert prediction model (solid line) in the transformed space. In this case, the software generated the curve by fitting a cubic to the transformed input response data (circles). The independent variable for the cubic curve at each point was the current longitude (CurrLng), and the dependent variable at each point was the square root of the quantity 110.55 added to the longitude at 24 hours beyond the current longitude. In many cases, the transformation does reduce the model coefficient uncertainty range, or reduce the predictive errors associated with the use of a given model, but not in all cases. Here, the standard deviation in the transformed space would be about 0.034 and the one-sided confidence interval about the intercept would be about 
0.02; as shown in Fig. 16, the LSD is reduced to about 0.052. In order to understand how this transformation would translate into improved model uncertainties and errors, the transformation must be reversed for each point of interest. That is to say that High, Nominal, and Low values for each response must be de-transformed independently and then compared in the untransformed space. For the case at hand, the model uncertainty computed from the intercept confidence interval would be $0.189 \mathrm{~nm}$ (compared to $12 \mathrm{~nm}$ above), or from the LSD would about the $50 \%$ prediction error would be about $0.915 \mathrm{~nm}$ (compared to $16 \mathrm{~nm}$ above), and the $95 \%$ prediction error would be about $0.12 \mathrm{~nm}$ (compared to $47 \mathrm{~nm}$ above). It is worth noting that some publications indicate this de-transformation process is not a recommended practice. Certainly, the inversion of a transformation can only reasonably be carried out in the manner described, i.e., an increment must be added to, or subtracted from, a relevant model value in the transformed space, each new value is de-transformed separately, and then differenced with the relevant model value in the untransformed space; no incremental value like a standard deviation, CI, or LSD, should be simply untransformed by itself.

Next, the prediction of latitude 24 hours after a given point in the Table 2 data set, from the current latitude only, is conducted using as similar process as that described above for the longitude. In this case, the normality distribution of the input data is poor. Other characteristics of the data set are quite similar to those previously shown. The resulting quadratic curve fit given in Eq. 1 to the input data is shown in Figure 19. In this case, the modeling uncertainty, as defined by the intercept $\mathrm{CI}$ is only $7 \mathrm{~nm}$, the $50 \%$ predictive error is $98 \mathrm{~nm}$, and the $95 \%$ predictive error is $283 \mathrm{~nm}$.

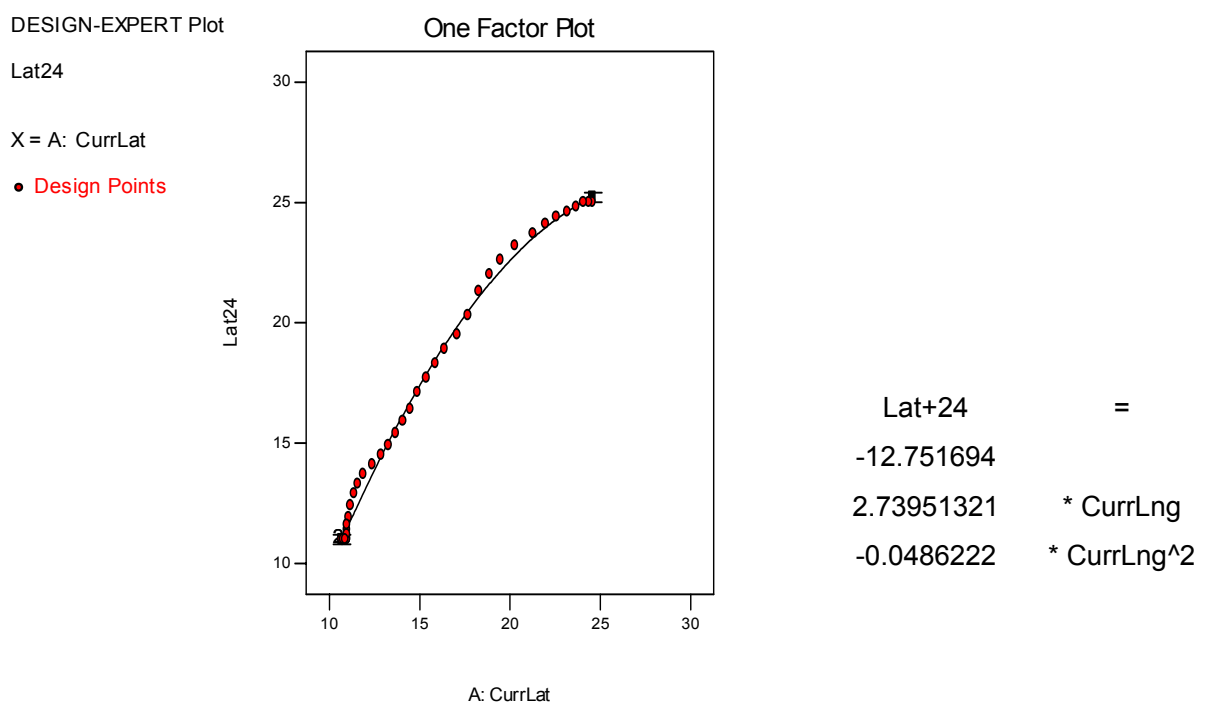

Figure 17. Design-Expert One-Factor plot Showing Lat +24 as a function of CurrLat.

The longitude model shown in lines 32-35 of Fig. 15 can be used with the latitude model shown above in Eq. 1 to determine how accurately the model would predict the behavior of the Hurricane Emily, if all of its movements were known in advance. Combining longitude and latitude results, with longitude corrections made using the predicted latitudes, summing the squared error components in the two directions, and then taking the square root to obtain the total error as a distance, it is found that the maximum track error would be about $63 \mathrm{~nm}$, the minimum track error would be about $6 \mathrm{~nm}$, the average track error would be about $29 \mathrm{~nm}$, with a standard deviation of about $15 \mathrm{~nm}$. It might be surprising to some people that, even if its movements were known in advance, a track prediction error occurs. This is simply because the Design-Expert model does not perfectly fit the data given; thus, some prediction error will always be present. 
To conclude this first demonstration, the current value of wind intensity (CurrWnd) is used to predict the wind intensity 24 hours in advance $(\mathrm{Wnd}+24)$ for Hurricane Emily. The normality distribution is poor. The one-sided model uncertainty determined from the intercept CI is only about 14 one knots $(\mathrm{kt})$, or 16 miles per hour $(\mathrm{mph})$. The one-sided $50 \%$ predictive error is about $18 \mathrm{kt}$. The $95 \%$ predictive error is about $51 \mathrm{kt}$. A summary of the various predictions for the longitude, latitude, track error, and wind speed for Hurricane Emily, assuming all the storm's track and intensity were known in advance, are presented in Tables 3 through 6, respectively. In Tables 3 through 6 , results of Analysis Type 1T (one temporal factor) use only the current longitude, latitude, or wind speed to predict a similar future quantity 24 or 48 hours in advance. Results of Analysis Type 2T (two temporal factors) use the current longitude, latitude, or wind speed and same quantity 24 hours previous, to predict a similar future quantity 24 hours in advance. Results of Analysis Type 3X (three crossed, or mixed, factors) use the current longitude, latitude, and wind speed together, to independently predict each one of these quantities 24 or 48 hours in advance. Finally, results of Analysis Type 9X (nine crossed, or mixed, factors) use the set of nine independent variables previously described together, to independently predict one of three quantities (longitude, latitude, or wind speed) 24 or 48 hours in advance. From Table 3, it can be seen that the 24-hour modeling uncertainty and prediction errors decreased slightly for the 1T Analysis Type as more data points were considered. A similar effect was observed for the 3X Analysis type, but not for the 9X Analysis Type. The 1T Analysis Type clearly has the smallest modeling uncertainty of the four analysis methods, whereas the $3 \mathrm{X}$ Analysis Type has the smallest prediction errors. Similar effects are also observed in Table 4 with the latitude. In Table 5, the track error, computed as the square root of the squared sum of similar elements from Tables 3 and 4, also has the same behavior; favorable comparisons are made in several instances with the achieved $50 \%$ and $95 \%$ prediction errors from the NHC; however, recall the ANOVA model uncertainty and prediction errors presented in Tables 3 through 5 assume that the behavior of Hurricane Emily were already known in advance. In Table 6, only the $3 \mathrm{X}$ Analysis Type cases fare better than the official intensity predictions from the NHC.

The results for applying the ANOVA technique to the entire set of hurricane data from 1851 to 2004 are now described. As noted before, and illustrated in Table 2, because of the way the data is presented to the software for use in 48-, 72-, 96-, and 120-hour track and intensity predictions, it is also possible to make predictions for shorter time intervals, but with fewer data points being considered. Thus the 48-hour data set can be used to make 24-hour predictions, but using 20368 data points, instead of the available 23490. Also, the data can be simply renamed from, for example, CurrLng, Lng+24, Lng+48, Lng+72, Lng+96, and Lng+120 to Lng-24, CurrLng, Lng+24, Lng+48, Lng+72, and Lng+9, respectively, which enables the type 2 analyses discussed previously (multiple temporal factors used to predict future behavior) when Table 2 was introduced. With this larger data set, two new variants of the multiple temporal factor analyses discussed in Tables 3 through 6 are introduced. These new Analysis Type 2 variants are the 3T (uses, for example, Lng-48, Lng-24, and CurrLng to predict Lng+24, Lng+48, Lng+72), and the 4T. The 4T Analysis Type uses, for example, Lng-72, Lng-48, Lng-24, and CurrLng to predict Lng+24 and Lng+48. Tables 7 through 10 summarize the application of the ANOVA technique to the complete specific data sets for each of the 24-, 48-, 72-, 96-, and 120-hour latitude predictions. A maximum of 23490 data points are available with which to make 24-hour predictions (see Case Index 22-24 of Table 3). It is expected that using more prior information should improve the forecasting ability since the tool can reasonably fit such groups of data with quadratic or cubic models of greater accuracy than is possible with the Type 1T analyses.

From Table 7, 8, and 9, it can be seen that the 24-hour modeling uncertainty and prediction errors increased slightly for the 1T Analysis Type as more data points were considered, in contrast to what was observed previously with the smaller data set. Similar effects are observed for the 48- to 96-hour predictions. As expected, the 2T, 3T, and 4T analysis types do improve upon the $1 \mathrm{~T}$ analysis type, indicating that using some previous information does indeed help to predict the future state, although the best results are obtained with just previous information from 24 hours before the current state. The $3 \mathrm{X}$ analysis type also improve the prediction accuracy over the 1T analysis type; even greater improvements are observed with the $9 \mathrm{X}$ analysis type, compared to $1 \mathrm{~T}$ analysis type. As expected, this indicates that the ANOVA technique is able to sort out data variability effects due to the various factors, but not to a sufficient degree to beat the experts at their forecasts. In all the 1T, 2T, 3T, and 4T cases, the modeling uncertainty is relatively small, perhaps negligible, because having chosen a specific model for prediction, the modeling uncertainty is somewhat irrelevant. As expected, in all cases the modeling uncertainties and prediction errors varied with the length of the projected forecast, i.e., 48-hour prediction errors are greater than similar errors for a 24-hour prediction. Surprisingly, as seen in Table 10, all of the maximum wind speed prediction accuracies are comparable to the NHC forecast accuracies. 
The best combined track model uncertainty and track prediction error results are obtained from the 2T analysis type, which is was used to predict across the calendar year 2005 hurricanes, with special interest in the prediction accuracy for the Category 5 hurricanes, as shown in Table 11. The best maximum track prediction performance was obtained for the application to Hurricane Emily data, though again the prediction errors were greater than $95 \%$ cumulative errors published by the NHC. The best average track prediction performance was obtained for the application to Hurricane Wilma data, which was slightly better than the NHC published prediction accuracy at both 24 and 72 hours, both highlighted in Table 11.

A final analysis was conducted in which the starting longitude, latitude, maximum sustained wind speed, and year fraction were used in an attempt to predict the maximum lifetime wind speed and total duration of storms. Again, data from 1851 to 2004 were analyzed, and the resulting models applied to the 2005 storm set. In this case, all storms were considered for both analysis and validation, since at the onset, it cannot be determined how strong a given storm will become, or how long it may last. Unfortunately, this study did not yield useful results for the 2005 season of storms. Since the residuals for each of the calculations are proportional to the goodness of the model fit to the input data, a second attempt was made using the same input variables, but with the absolute values of the predictive errors (residuals) from the previous exercise used as the input responses in this second study.

The predictive models developed by fitting the residuals, noted above, as functions of the starting longitude, latitude, maximum sustained wind speed, and year fraction, for the 1851 to 2004 storm set, were applied to each of the 2005 storms in order to determine if the ANOVA technique could discern from a storm's initial conditions whether it would be "difficult to predict" (i.e., predictive errors greater than the average). Of the 28 storms during the 2005 season, nine of the storms would be "difficult to predict" in the maximum lifetime sustained wind speed, and 12 would be "difficult to predict" in total storm duration from just the initial location, intensity, and year fraction. Of those nine storms for which the maximum lifetime sustained wind would be deemed "difficult to predict" this screening method correctly identified seven (78\%), with two misses, most notably on Hurricane Katrina. Of the 12 storms for which the maximum duration would be "difficult to predict", the screening method correctly identified $67 \%$. Considering the correct identification of both "easy to predict" and "difficult to predict" storms, the success rate is only $64 \%$, with a $25 \%$ false alarm rate (maximum lifetime sustained wind falsely indicated as "difficult to predict" from its initial conditions), and an $11 \%$ miss rate for the maximum lifetime sustained wind speed; the method was even less accurate for correctly determining the ultimate predictability of the storm duration. This screening technique did, however, correctly identify four of the five Category 4 and 5 hurricanes (Dennis, Emily, Rita, and Wilma) during the 2005 season as "difficult to predict", and correctly identified one Category 3 hurricane as "easy to predict". So, for high intensity hurricanes, of most concern for emergency operations planning, this technique would have correctly identified $71 \%$ as possibly requiring "special attention" in their modeling.

\section{Conclusions}

A demonstration of applying the Analysis of Variance (ANOVA) technique to historical hurricane track data was presented. In general, wind intensity predictions were as good as, or better than, those equivalent prediction metrics produced by the National Hurricane Center (NHC). Latitude model uncertainties and prediction errors were generally smaller than comparable longitude model uncertainties and prediction errors. Modeling uncertainties and prediction errors generally grew larger as the prediction period increased from 24 to 120 hours. In general, modeling uncertainties grew larger as more factors were considered, but prediction errors decreased as more factors were considered. This indicates that the ANOVA technique was able to allocate variation among the data entries better as more variables were considered. Although very few of the ANOVA predictions were better than those from the NHC, the ANOVA technique still did fairly well with predictions from a large data set exhibiting a great amount of variability, and despite the inclusion of storms which deviated significantly from an expected east to west progression, in the North Atlantic Ocean, toward North America. A validation exercise was conducted in which the predictive models developed through the ANOVA technique were applied to four Category 5 hurricanes from calendar year 2005. The best maximum track prediction performance was obtained for the application to Hurricane Emily data, though again the prediction errors were greater than $95 \%$ cumulative errors published by the NHC. The best average track prediction performance was obtained for the application to Hurricane Wilma data, which was slightly better than the NHC published prediction accuracy at both 24 and 72 hours. An additional technique was discussed in which the ANOVA method was used to screen storms at their onset as to their ultimate predictability with respect to maximum lifetime sustained winds and storm duration. 


\section{References}

1. Fisher, Ronald A., "Statistical Methods for Research Workers", ISBN 0050021702, Oliver and Boyd, Edinburgh England, 1925.

2. John, Robert, "Elementary Statistics ( $7^{\text {th }}$ Edition)", Duxbury Press / Wadsworth Publishing Company, Cincinnati, OH, 1996.

3. Carnahan, Brice, Luther, H. A., and Wilkes, James O., “Applied Numerical Methods”, John Wiley \& Sons Publishing, New York NY, 1976.

4. Duncan, James, "The Really Easy Statistics Site (TRESS)"

http:/helios.bto.ed.ac.uk/bto/statistics/tress1.html\#THE\%20REALLY\%20EASY\%20STATISTICS\%20SITE.

5. Ramirez-Beltran, Nazario D., and Castro, Joan Manuel, "Upper Air Data and Time Series Analysis to Predict Hurricane Track", http://www.cmg.uprm.edu/papers/Hurricane-Season-05-NR.pdf (no conference name or paper number available).

6. Fovell, Robert G., " Impact of microphysics on hurricane track and intensity forecasts", $7^{\text {th }}$ WRF User's Workshop, National Center for Atmospheric Research, 2006, http://www.mmm.ucar.edu/wrf/users/workshops/WS2006/abstracts/Session03/3_2_Fovell.pdf.

7. Park, Seon K., and Zhang, Da-Lin, "Impact of Dropwindsonde Data on Hurricane Track Forecasts", Third US-Korea Joint Workshop on Storm- and Mesoscale Weather Analysis and Prediction, February 2002, http://ams.confex.com/ams/pdfpapers/73611.pdf.

8. Goerss, James S., "Estimation of Tropical Cyclone Track Forecast Uncertainty", Naval Research Lab, Marine Meteorology Division, Monteray California PROCEEDINGS PAPERS -- CY2004, http://ams.confex.com/ams/pdfpapers/75241.pdf.

9. Stat-Ease, Inc "Design, Analyze, and Optimize with Design-Expert" Analytical Chemistry, 2002 Volume 74, Number 7, Pages 222 A-223 A.

10. Anderson, Mark J., and Whitcomb, Patrick J., "DOE Simplified: Practical Tools for Effective Experimentation" Productivity Press, ISBN: J-56327-225-3,Alk. Paper, 231 pages. Published May 2000, Copyright 2000, Productivity, Inc.

11. Anderson, Mark J., and Whitcomb, Patrick J., "RSM Simplified: Optimizing Processes Using Response Surface Methods for Design of Experiments" ISBN: 1-56327-297-0, 292 pages Published November 2004, Copyright 2005, Productivity, Inc.

12. David Howie, "Interpreting Probability: Controversies and Developments in the Early Twentieth Century" (Cambridge University Press, 2002)

Table 1. The Saffir-Simpson Hurricane Scale

\begin{tabular}{|c|c|c|c|}
\hline Category & $\begin{array}{c}\text { Sustained } \\
\text { Winds } \\
\text { mph } \\
\text { (kt) }\end{array}$ & $\begin{array}{c}\text { Storm } \\
\text { Surge } \\
\text { (ft) }\end{array}$ & Potential Damage \\
\hline $\mathbf{1}$ & $\begin{array}{c}74-95 \\
(64-82)\end{array}$ & $4-5$ & $\begin{array}{c}\text { No real damage to building structures. Damage primarily to } \\
\text { unanchored mobile homes, shrubbery, and trees. Also, some } \\
\text { coastal flooding and minor pier damage. }\end{array}$ \\
\hline $\mathbf{2}$ & $96-110$ & $6-8$ & $\begin{array}{c}\text { Some roofing material, door, and window damage. } \\
\text { Considerable damage to vegetation, mobile homes, etc. } \\
\text { Flooding damages piers and small craft in unprotected boats } \\
\text { may break their moorings. }\end{array}$ \\
\hline $\mathbf{3}$ & $\begin{array}{c}(111-130 \\
(96-112)\end{array}$ & $9-12$ & $\begin{array}{c}\text { Some structural damage to small residences and utility } \\
\text { buildings, with a minor amount of curtain wall failures. Mobile } \\
\text { homes are destroyed. Flooding near the coast destroys smaller } \\
\text { structures with larger structures damaged by floating debris. } \\
\text { Terrain may be flooded well inland. }\end{array}$ \\
\hline $\mathbf{5}$ & $\begin{array}{c}\text { 131-155 } \\
(113-134)\end{array}$ & $13-18$ & $\begin{array}{c}\text { More extensive curtain wall failures with some complete roof } \\
\text { structure failure on small residences. Major erosion of beach } \\
\text { areas. Terrain may be flooded well inland. }\end{array}$ \\
\hline$>=156$ & $>=135)$ & $\begin{array}{c}\text { Complete roof failure on many residences and industrial } \\
\text { buildings. Some complete building failures with small utility } \\
\text { buildings blown over or away. Flooding causes major damage } \\
\text { to lower floors of all structures near the shoreline. Massive } \\
\text { evacuation of residential areas may be required. }\end{array}$ \\
\hline
\end{tabular}

All wind speeds are based on a one-minute average.

Intensity of example hurricanes is from both the time of landfall and the maximum intensity. From http://en.wikipedia.org/wiki/Saffir-Simpson_Hurricane_Scale 
AIAA-2007-1101 - Lawrence L. Green

Table 2. The History of Hurricane Emily (July 2005)

\begin{tabular}{|c|c|c|c|c|c|c|c|}
\hline Reading & Date & $\begin{array}{c}\text { Time } \\
\text { Hours Zulu }\end{array}$ & $\begin{array}{c}\text { Longitude } \\
\text { degrees }\end{array}$ & $\begin{array}{l}\text { Latitude } \\
\text { degrees }\end{array}$ & $\begin{array}{l}\text { Wind } \\
\text { Speed } \\
\text { knots }\end{array}$ & $\begin{array}{c}\text { Longitude } \\
\text { at } \\
T+24 \text { Hours } \\
\text { degrees }\end{array}$ & $\begin{array}{c}\text { Longitude } \\
\text { at } \\
T+48 \text { Hours } \\
\text { degrees }\end{array}$ \\
\hline 1 & $7 / 11 / 2005$ & $0000 Z$ & -42.4 & 10.7 & 25 & -46.8 & -53.7 \\
\hline 2 & $7 / 11 / 2005$ & $0600 Z$ & -43.4 & 10.8 & 30 & -48.5 & -55.4 \\
\hline 3 & $7 / 11 / 2005$ & $1200 Z$ & -44.4 & 10.9 & 30 & -50.2 & -57.2 \\
\hline 4 & $7 / 11 / 2005$ & $1800 Z$ & -45.4 & 11 & 30 & -52 & -58.9 \\
\hline 5 & $7 / 12 / 2005$ & $0000 Z$ & -46.8 & 11 & 35 & -53.7 & -60.2 \\
\hline 6 & $7 / 12 / 2005$ & $0600 Z$ & -48.5 & 11 & 40 & -55.4 & -61.5 \\
\hline 7 & $7 / 12 / 2005$ & $1200 Z$ & -50.2 & 11 & 45 & -57.2 & -63.2 \\
\hline 8 & $7 / 12 / 2005$ & $1800 Z$ & -52 & 11 & 45 & -58.9 & -64.9 \\
\hline 9 & $7 / 13 / 2005$ & $0000 Z$ & -53.7 & 11 & 45 & -60.2 & -66.7 \\
\hline 10 & $7 / 13 / 2005$ & $0600 Z$ & -55.4 & 11.1 & 45 & -61.5 & -68.4 \\
\hline 11 & $7 / 13 / 2005$ & $1200 Z$ & -57.2 & 11.2 & 50 & -63.2 & -70.1 \\
\hline 12 & $7 / 13 / 2005$ & $1800 Z$ & -58.9 & 11.4 & 55 & -64.9 & -71.8 \\
\hline 13 & $7 / 14 / 2005$ & $0000 Z$ & -60.2 & 11.6 & 70 & -66.7 & -73.4 \\
\hline 14 & $7 / 14 / 2005$ & $0600 Z$ & -61.5 & 11.9 & 75 & -68.4 & -75 \\
\hline 15 & $7 / 14 / 2005$ & $1200 Z$ & -63.2 & 12.4 & 85 & -70.1 & -76.5 \\
\hline 16 & $7 / 14 / 2005$ & $1800 Z$ & -64.9 & 12.9 & 100 & -71.8 & -78 \\
\hline 17 & $7 / 15 / 2005$ & $0000 Z$ & -66.7 & 13.3 & 110 & -73.4 & -79.5 \\
\hline 18 & $7 / 15 / 2005$ & $0600 Z$ & -68.4 & 13.7 & 115 & -75 & -81.2 \\
\hline 19 & $7 / 15 / 2005$ & $1200 Z$ & -70.1 & 14.1 & 115 & -76.5 & -82.8 \\
\hline 20 & $7 / 15 / 2005$ & $1800 Z$ & -71.8 & 14.5 & 95 & -78 & -84.3 \\
\hline 21 & $7 / 16 / 2005$ & $0000 Z$ & -73.4 & 14.9 & 110 & -79.5 & -85.8 \\
\hline 22 & $7 / 16 / 2005$ & $0600 Z$ & -75 & 15.4 & 120 & -81.2 & -87.3 \\
\hline 23 & $7 / 16 / 2005$ & $1200 Z$ & -76.5 & 15.9 & 130 & -82.8 & -88.9 \\
\hline 24 & $7 / 16 / 2005$ & $1800 Z$ & -78 & 16.4 & 135 & -84.3 & -90.3 \\
\hline 25 & $7 / 17 / 2005$ & $0000 Z$ & -79.5 & 17.1 & 140 & -85.8 & -91.5 \\
\hline 26 & $7 / 17 / 2005$ & $0600 Z$ & -81.2 & 17.7 & 135 & -87.3 & -92.8 \\
\hline 27 & $7 / 17 / 2005$ & $1200 Z$ & -82.8 & 18.3 & 130 & -88.9 & -94 \\
\hline 28 & $7 / 17 / 2005$ & $1800 Z$ & -84.3 & 18.9 & 125 & -90.3 & -95.1 \\
\hline 29 & $7 / 18 / 2005$ & $0000 Z$ & -85.8 & 19.5 & 120 & -91.5 & -96.1 \\
\hline 30 & $7 / 18 / 2005$ & $0600 Z$ & -87.3 & 20.3 & 115 & -92.8 & -96.9 \\
\hline 31 & $7 / 18 / 2005$ & $1200 Z$ & -88.9 & 21.3 & 65 & -94 & -97.6 \\
\hline 32 & $7 / 18 / 2005$ & $1800 Z$ & -90.3 & 22 & 65 & -95.1 & -98.7 \\
\hline 33 & $7 / 19 / 2005$ & $0000 Z$ & -91.5 & 22.6 & 75 & -96.1 & -99.7 \\
\hline 34 & $7 / 19 / 2005$ & $0600 Z$ & -92.8 & 23.2 & 80 & -96.9 & -100.5 \\
\hline 35 & $7 / 19 / 2005$ & $1200 Z$ & -94 & 23.7 & 80 & -97.6 & \\
\hline 36 & $7 / 19 / 2005$ & $1800 Z$ & -95.1 & 24.1 & 85 & -98.7 & \\
\hline 37 & $7 / 20 / 2005$ & $0000 Z$ & -96.1 & 24.4 & 110 & -99.7 & \\
\hline 38 & $7 / 20 / 2005$ & $0600 Z$ & -96.9 & 24.6 & 110 & -100.5 & \\
\hline 39 & $7 / 20 / 2005$ & $1200 Z$ & -97.6 & 24.8 & 110 & & \\
\hline 40 & $7 / 20 / 2005$ & $1800 Z$ & -98.7 & 25 & 70 & & \\
\hline 41 & $7 / 21 / 2005$ & $0000 Z$ & -99.7 & 25 & 45 & & \\
\hline 42 & $7 / 21 / 2005$ & $0600 Z$ & -100.5 & 25 & 30 & & \\
\hline
\end{tabular}


Table 3. Uncertainty Analysis for Longitude (Hurricane Emily, track known)

\begin{tabular}{|c|c|c|c|c|c|c|c|c|}
\hline $\begin{array}{l}\text { Case } \\
\text { Index }\end{array}$ & $\begin{array}{l}\text { Number of } \\
\text { Data Points }\end{array}$ & Response & $\begin{array}{c}\text { Analysis } \\
\text { Type }\end{array}$ & $\begin{array}{c}\text { Intercept } \\
95 \% \\
\text { Confidence } \\
\text { Interval } \\
\text { degrees } \\
\end{array}$ & $\begin{array}{c}\text { Standard } \\
\text { Deviation } \\
\text { degrees }\end{array}$ & $\begin{array}{c}\text { ANOVA } \\
\text { Model } \\
\text { Uncertainty } \\
\text { nm }\end{array}$ & $\begin{array}{c}\text { ANOVA } \\
50 \% \\
\text { Prediction } \\
\text { Error } \\
\mathrm{nm} \\
\end{array}$ & $\begin{array}{c}\text { ANOVA } \\
95 \% \\
\text { Prediction } \\
\text { Error } \\
\mathrm{nm} \\
\end{array}$ \\
\hline 1 & 34 & Lng24 & $1 \mathrm{~T}$ & 0.49 & 0.46 & 13 & 16 & 48 \\
\hline 2 & 38 & Lng24 & $1 \mathrm{~T}$ & 0.46 & 0.45 & 12 & 16 & 47 \\
\hline 3 & 34 & Lng48 & $1 \mathrm{~T}$ & 0.41 & 0.38 & 11 & 13 & 39 \\
\hline 4 & 34 & Lng24 & $2 \mathrm{~T}$ & 58.92 & 0.17 & 1548 & 6 & 17 \\
\hline 5 & 34 & Lng24 & $3 X$ & 17.30 & 0.08 & 454 & 3 & 8 \\
\hline 6 & 38 & Lng24 & $3 X$ & 9.85 & 0.09 & 259 & 3 & 10 \\
\hline 7 & 34 & Lng48 & $3 X$ & 16.98 & 0.08 & 446 & 3 & 8 \\
\hline 8 & 34 & Lng24 & $9 x$ & 10.84 & 15.53 & 285 & 550 & 1599 \\
\hline 9 & 38 & Lng24 & $9 X$ & 10.98 & 16.70 & 288 & 592 & 1720 \\
\hline 10 & 34 & Lng48 & $9 x$ & 10.23 & 14.65 & 269 & 519 & 1509 \\
\hline
\end{tabular}

Table 4. Uncertainty Analysis for Latitude (Hurricane Emily, track known)

\begin{tabular}{|c|c|c|c|c|c|c|c|c|}
\hline $\begin{array}{l}\text { Case } \\
\text { Index }\end{array}$ & $\begin{array}{l}\text { Number of } \\
\text { Data Points }\end{array}$ & Response & $\begin{array}{c}\text { Analysis } \\
\text { Type }\end{array}$ & $\begin{array}{c}\text { Intercept } \\
95 \% \\
\text { Confidence } \\
\text { Interval } \\
\text { degrees } \\
\end{array}$ & $\begin{array}{c}\text { Standard } \\
\text { Deviation } \\
\text { degrees }\end{array}$ & $\begin{array}{c}\text { ANOVA } \\
\text { Model } \\
\text { Uncertainty } \\
\text { nm }\end{array}$ & $\begin{array}{c}\text { ANOVA } \\
50 \% \\
\text { Prediction } \\
\text { Error } \\
\mathrm{nm}\end{array}$ & $\begin{array}{c}\text { ANOVA } \\
95 \% \\
\text { Prediction } \\
\text { Error } \\
\mathrm{nm}\end{array}$ \\
\hline 1 & 34 & Lat24 & $1 \mathrm{~T}$ & 0.44 & 0.37 & 13 & 15 & 44 \\
\hline 2 & 38 & Lat24 & $1 \mathrm{~T}$ & 0.42 & 0.36 & 13 & 15 & 42 \\
\hline 3 & 34 & Lat48 & $1 \mathrm{~T}$ & 0.75 & 0.62 & 23 & 26 & 74 \\
\hline 4 & 34 & Lat24 & $2 \mathrm{~T}$ & 20.72 & 0.29 & 629 & 12 & 34 \\
\hline 5 & 34 & Lat24 & $3 X$ & 10.65 & 0.05 & 323 & 2 & 6 \\
\hline 6 & 38 & Lat24 & $3 X$ & 5.53 & 0.05 & 168 & 2 & 6 \\
\hline 7 & 34 & Lat48 & $3 X$ & 8.97 & 0.04 & 272 & 2 & 5 \\
\hline 8 & 34 & Lat24 & $9 X$ & 3.32 & 4.76 & 101 & 195 & 566 \\
\hline 9 & 38 & Lat24 & $9 x$ & 3.45 & 5.24 & 105 & 214 & 623 \\
\hline 10 & 34 & Lat48 & $9 X$ & 3.53 & 5.06 & 107 & 207 & 602 \\
\hline
\end{tabular}


Table 5. Uncertainty Analysis for Track Error (Hurricane Emily, track known)

\begin{tabular}{|c|c|c|c|c|c|c|c|c|}
\hline $\begin{array}{c}\text { Case } \\
\text { Index }\end{array}$ & $\begin{array}{c}\text { Number of } \\
\text { Data Points }\end{array}$ & Response & $\begin{array}{c}\text { Analysis } \\
\text { Type }\end{array}$ & $\begin{array}{c}\text { ANOVA } \\
\text { Model } \\
\text { Uncertainty } \\
\mathbf{n m}\end{array}$ & $\begin{array}{c}\text { ANOVA } \\
\mathbf{5 0 \%} \\
\text { Prediction } \\
\text { Error } \\
\mathbf{n m}\end{array}$ & $\begin{array}{c}\text { ANOVA } \\
\mathbf{9 5 \%} \\
\text { Prediction } \\
\text { Error } \\
\mathbf{n m}\end{array}$ & $\begin{array}{c}\text { NHC 50\% } \\
\text { Prediction } \\
\text { Error } \\
\mathbf{n m}\end{array}$ & $\begin{array}{c}\text { NHC 95\% } \\
\text { Prediction } \\
\text { Error } \\
\mathbf{n m}\end{array}$ \\
\hline 1 & 34 & Track24 & $1 \mathrm{~T}$ & 19 & 22 & 65 & 55 & 140 \\
\hline 2 & 38 & Track24 & $1 \mathrm{~T}$ & 18 & 22 & 63 & 55 & 140 \\
\hline 3 & 34 & Track48 & $1 \mathrm{~T}$ & 25 & 29 & 84 & 100 & 270 \\
\hline 4 & 34 & Track24 & $2 \mathrm{~T}$ & 1670 & 13 & 38 & 55 & 140 \\
\hline 5 & 34 & Track24 & $3 \mathrm{X}$ & 558 & 4 & 10 & 55 & 140 \\
\hline 6 & 38 & Track24 & $3 \mathrm{X}$ & 308 & 4 & 11 & 55 & 140 \\
\hline 7 & 34 & Track48 & $3 \mathrm{X}$ & 523 & 3 & 10 & 100 & 270 \\
\hline 8 & 34 & Track24 & $9 \mathrm{X}$ & 302 & 584 & 1697 & 55 & 140 \\
\hline 9 & 38 & Track24 & $9 \mathrm{X}$ & 307 & 629 & 1829 & 55 & 140 \\
\hline 10 & 34 & Track48 & $9 \mathrm{X}$ & 289 & 559 & 1625 & 100 & 270 \\
\hline
\end{tabular}

Table 6. Uncertainty Analysis for Wind Speed (Hurricane Emily, intensity known)

\begin{tabular}{|c|c|c|c|c|c|c|c|c|}
\hline $\begin{array}{l}\text { Case } \\
\text { Index }\end{array}$ & $\begin{array}{l}\text { Number of } \\
\text { Data Points }\end{array}$ & Response & $\begin{array}{c}\text { Analysis } \\
\text { Type }\end{array}$ & $\begin{array}{c}\text { ANOVA } \\
\text { Model } \\
\begin{array}{c}\text { Uncertainty } \\
\text { kt }\end{array}\end{array}$ & $\begin{array}{c}\text { ANOVA } \\
\mathbf{5 0 \%} \\
\text { Prediction } \\
\text { Error } \\
\mathbf{k t} \\
\end{array}$ & $\begin{array}{c}\text { ANOVA } \\
95 \% \\
\text { Prediction } \\
\text { Error } \\
\text { kt } \\
\end{array}$ & $\begin{array}{l}\text { NHC 50\% } \\
\text { Prediction } \\
\text { Error } \\
\text { kt }\end{array}$ & $\begin{array}{l}\text { NHC 95\% } \\
\text { Prediction } \\
\text { Error } \\
\text { kt }\end{array}$ \\
\hline 1 & 38 & Wnd24 & $1 \mathrm{~T}$ & 14 & 18 & 51 & 10 & 30 \\
\hline 2 & 34 & Wnd24 & $1 \mathrm{~T}$ & 12 & 13 & 39 & 10 & 30 \\
\hline 3 & 34 & Wnd48 & $1 \mathrm{~T}$ & 15 & 17 & 50 & 10 & 40 \\
\hline 4 & 34 & Wnd24 & $2 \mathrm{~T}$ & 13 & 19 & 54 & 10 & 30 \\
\hline 5 & 38 & Wnd24 & $3 x$ & 420 & 5 & 15 & 10 & 30 \\
\hline 6 & 34 & Wnd24 & $3 x$ & 735 & 5 & 14 & 10 & 30 \\
\hline 7 & 34 & Wnd48 & $3 X$ & 774 & 5 & 14 & 10 & 40 \\
\hline 8 & 38 & Wnd24 & $9 x$ & 11 & 23 & 65 & 10 & 30 \\
\hline 9 & 34 & Wnd24 & $9 x$ & 11 & 22 & 64 & 10 & 30 \\
\hline 10 & 34 & Wnd48 & $9 x$ & 11 & 21 & 61 & 10 & 40 \\
\hline
\end{tabular}


AIAA-2007-1101 - Lawrence L. Green

Table 7. Uncertainty Analysis for Longitude (1851-2004 Hurricanes)

\begin{tabular}{|c|c|c|c|c|c|c|c|c|}
\hline $\begin{array}{l}\text { Case } \\
\text { Index }\end{array}$ & $\begin{array}{l}\text { Number of } \\
\text { Data Points }\end{array}$ & Response & $\begin{array}{l}\text { Analysis } \\
\text { Type }\end{array}$ & $\begin{array}{l}\text { Intercept } \\
95 \% \\
\text { Confidence } \\
\text { Interval } \\
\text { degrees }\end{array}$ & $\begin{array}{c}\text { Standard } \\
\text { Deviation } \\
\text { degrees }\end{array}$ & $\begin{array}{c}\text { ANOVA } \\
\text { Model } \\
\text { Uncertainty } \\
\text { nm }\end{array}$ & $\begin{array}{l}\text { ANOVA } \\
50 \% \\
\text { Prediction } \\
\text { Error } \\
\mathrm{nm}\end{array}$ & $\begin{array}{l}\text { ANOVA } \\
95 \% \\
\text { Prediction } \\
\text { Error } \\
\mathrm{nm}\end{array}$ \\
\hline 1 & 11958 & Lng24 & $1 \mathrm{~T}$ & 0.16 & 3.07 & 4 & 109 & 316 \\
\hline 2 & 14561 & Lng24 & $1 \mathrm{~T}$ & 0.15 & 3.38 & 4 & 120 & 348 \\
\hline 3 & 17378 & Lng24 & $1 \mathrm{~T}$ & 0.21 & 3.83 & 5 & 136 & 394 \\
\hline 4 & 20368 & Lng24 & $1 \mathrm{~T}$ & 0.21 & 4.38 & 6 & 155 & 451 \\
\hline 5 & 23490 & Lng24 & $1 \mathrm{~T}$ & 0.23 & 5.02 & 6 & 178 & 517 \\
\hline 6 & 11958 & Lng48 & $1 \mathrm{~T}$ & 0.31 & 6.09 & 8 & 216 & 627 \\
\hline 7 & 14561 & Lng48 & $1 \mathrm{~T}$ & 0.31 & 6.86 & 8 & 243 & 706 \\
\hline 8 & 17378 & Lng48 & $1 \mathrm{~T}$ & 0.42 & 7.84 & 11 & 278 & 807 \\
\hline 9 & 20368 & Lng48 & $1 \mathrm{~T}$ & 0.44 & 9.05 & 12 & 321 & 932 \\
\hline 10 & 11958 & Lng72 & $1 \mathrm{~T}$ & 0.44 & 9.21 & 11 & 326 & 948 \\
\hline 11 & 14561 & Lng72 & $1 \mathrm{~T}$ & 0.49 & 10.51 & 13 & 372 & 1082 \\
\hline 12 & 17378 & Lng72 & $1 \mathrm{~T}$ & 0.65 & 12.13 & 17 & 430 & 1249 \\
\hline 13 & 11958 & Lng96 & $1 \mathrm{~T}$ & 0.60 & 12.54 & 16 & 444 & 1291 \\
\hline 14 & 14561 & Lng96 & $1 \mathrm{~T}$ & 0.68 & 14.46 & 18 & 512 & 1489 \\
\hline 15 & 11958 & Lng120 & $1 \mathrm{~T}$ & 0.82 & 16.20 & 22 & 574 & 1668 \\
\hline 16 & 11958 & Lng24 & $2 T$ & 0.17 & 1.86 & 4 & 66 & 191 \\
\hline 17 & 14561 & Lng24 & $2 T$ & 0.17 & 2.07 & 4 & 73 & 214 \\
\hline 18 & 17378 & Lng24 & $2 T$ & 0.17 & 2.35 & 4 & 83 & 242 \\
\hline 19 & 20368 & Lng24 & $2 \mathrm{~T}$ & 0.17 & 2.63 & 5 & 93 & 271 \\
\hline 20 & 11958 & Lng48 & $2 T$ & 0.41 & 4.61 & 11 & 163 & 474 \\
\hline 21 & 14561 & Lng48 & $2 T$ & 0.41 & 5.19 & 11 & 184 & 534 \\
\hline 22 & 17378 & Lng48 & $2 T$ & 0.42 & 5.91 & 11 & 209 & 608 \\
\hline 23 & 11958 & Lng72 & $2 T$ & 0.71 & 7.91 & 19 & 280 & 814 \\
\hline 24 & 14561 & Lng72 & $2 T$ & 0.72 & 9.02 & 19 & 320 & 929 \\
\hline 25 & 11958 & Lng96 & $2 T$ & 1.06 & 11.74 & 28 & 416 & 1209 \\
\hline 26 & 11958 & Lng24 & $3 T$ & 0.20 & 2.02 & 5 & 72 & 208 \\
\hline 27 & 14561 & Lng24 & $3 T$ & 0.20 & 2.30 & 5 & 81 & 237 \\
\hline 28 & 17378 & Lng24 & $3 T$ & 0.20 & 2.56 & 5 & 91 & 263 \\
\hline 29 & 11958 & Lng48 & $3 T$ & 0.50 & 5.19 & 13 & 184 & 535 \\
\hline 30 & 14561 & Lng48 & $3 T$ & 0.51 & 5.90 & 13 & 209 & 608 \\
\hline 31 & 11958 & Lng72 & $3 T$ & 0.89 & 9.15 & 23 & 324 & 942 \\
\hline 32 & 11958 & Lng24 & $4 T$ & 0.24 & 2.35 & 6 & 83 & 242 \\
\hline 33 & 14561 & Lng24 & $4 \mathrm{~T}$ & 0.24 & 2.63 & 6 & 93 & 271 \\
\hline 34 & 11958 & Lng48 & $4 T$ & 0.63 & 6.07 & 16 & 215 & 625 \\
\hline 35 & 11958 & Lng24 & $3 x$ & 0.28 & 2.31 & 7 & 82 & 238 \\
\hline 36 & 14561 & Lng24 & $3 x$ & 0.25 & 2.48 & 7 & 88 & 255 \\
\hline 37 & 17378 & Lng24 & $3 x$ & 0.24 & 2.72 & 6 & 97 & 281 \\
\hline 38 & 20368 & Lng24 & $3 x$ & 0.23 & 2.99 & 6 & 106 & 308 \\
\hline 39 & 23490 & Lng24 & $3 x$ & 0.23 & 3.30 & 6 & 117 & 339 \\
\hline 40 & 11958 & Lng48 & $3 X$ & 0.55 & 4.62 & 14 & 164 & 476 \\
\hline 41 & 14561 & Lng48 & $3 x$ & 0.51 & 5.08 & 13 & 180 & 523 \\
\hline
\end{tabular}


AIAA-2007-1101 - Lawrence L. Green

\begin{tabular}{|c|c|c|c|c|c|c|c|c|}
\hline 42 & 17378 & Lng48 & $3 X$ & 0.48 & 5.61 & 13 & 199 & 578 \\
\hline 43 & 20368 & Lng48 & $3 X$ & 0.48 & 6.23 & 13 & 221 & 641 \\
\hline 44 & 11958 & Lng72 & $3 X$ & 0.85 & 7.11 & 22 & 252 & 732 \\
\hline 45 & 14561 & Lng72 & $3 X$ & 0.79 & 7.93 & 21 & 281 & 816 \\
\hline 46 & 17378 & Lng72 & $3 X$ & 0.77 & 8.86 & 20 & 314 & 912 \\
\hline 47 & 11958 & Lng96 & $3 X$ & 1.18 & 9.90 & 31 & 351 & 1019 \\
\hline 48 & 14561 & Lng96 & $3 X$ & 1.12 & 11.16 & 29 & 395 & 1149 \\
\hline 49 & 11958 & Lng120 & $3 X$ & 1.56 & 13.07 & 41 & 463 & 1346 \\
\hline 50 & 11958 & Lng24 & $9 X$ & 3.62 & 1.93 & 95 & 69 & 199 \\
\hline 51 & 14561 & Lng24 & $9 x$ & 3.03 & 2.12 & 80 & 75 & 219 \\
\hline 52 & 17378 & Lng24 & $9 x$ & 2.72 & 2.39 & 71 & 85 & 246 \\
\hline 53 & 20368 & Lng24 & $9 x$ & 1.73 & 2.70 & 45 & 96 & 278 \\
\hline 54 & 23490 & Lng24 & $9 x$ & 1.51 & 3.06 & 40 & 109 & 315 \\
\hline 55 & 11958 & Lng48 & $9 X$ & 7.41 & 3.96 & 195 & 140 & 408 \\
\hline 56 & 14561 & Lng48 & $9 x$ & 6.35 & 4.46 & 167 & 158 & 459 \\
\hline 57 & 17378 & Lng48 & $9 X$ & 5.32 & 5.01 & 140 & 178 & 516 \\
\hline 58 & 20368 & Lng48 & $9 X$ & 3.68 & 5.76 & 97 & 204 & 593 \\
\hline 59 & 11958 & Lng72 & $9 x$ & 11.64 & 6.23 & 306 & 221 & 641 \\
\hline 60 & 14561 & Lng72 & $9 x$ & 10.12 & 7.09 & 266 & 251 & 731 \\
\hline 61 & 17378 & Lng72 & $9 X$ & 8.53 & 8.04 & 224 & 285 & 828 \\
\hline 62 & 11958 & Lng96 & $9 X$ & 16.50 & 8.83 & 434 & 313 & 909 \\
\hline 63 & 14561 & Lng96 & $9 x$ & 14.48 & 10.15 & 380 & 360 & 1045 \\
\hline 64 & 11958 & Lng120 & $9 x$ & 22.16 & 11.85 & 582 & 420 & 1220 \\
\hline
\end{tabular}

Table 8. Uncertainty Analysis for Latitude (1851-2004 Hurricanes)

\begin{tabular}{|c|c|c|c|c|c|c|c|c|}
\hline $\begin{array}{l}\text { Case } \\
\text { Index }\end{array}$ & $\begin{array}{l}\text { Number of } \\
\text { Data Points }\end{array}$ & Response & $\begin{array}{c}\text { Analysis } \\
\text { Type }\end{array}$ & $\begin{array}{c}\text { Intercept } \\
95 \% \\
\text { Confidence } \\
\text { Interval } \\
\text { degrees } \\
\end{array}$ & $\begin{array}{c}\text { Standard } \\
\text { Deviation } \\
\text { degrees }\end{array}$ & $\begin{array}{c}\text { ANOVA } \\
\text { Model } \\
\text { Uncertainty } \\
\text { nm }\end{array}$ & $\begin{array}{c}\text { ANOVA } \\
50 \% \\
\text { Prediction } \\
\text { Error } \\
\text { nm }\end{array}$ & $\begin{array}{c}\text { ANOVA } \\
95 \% \\
\text { Prediction } \\
\text { Error } \\
\mathrm{nm} \\
\end{array}$ \\
\hline 1 & 11958 & Lat24 & $1 \mathrm{~T}$ & 0.10 & 1.56 & 3 & 64 & 185 \\
\hline 2 & 14561 & Lat24 & $1 \mathrm{~T}$ & 0.09 & 1.69 & 3 & 69 & 200 \\
\hline 3 & 17378 & Lat24 & $1 \mathrm{~T}$ & 0.08 & 1.84 & 3 & 75 & 218 \\
\hline 4 & 20368 & Lat24 & $1 \mathrm{~T}$ & 0.08 & 2.04 & 2 & 83 & 242 \\
\hline 5 & 23490 & Lat24 & $1 T$ & 0.08 & 2.27 & 2 & 93 & 270 \\
\hline 6 & 11958 & Lat48 & $1 \mathrm{~T}$ & 0.19 & 2.95 & 6 & 121 & 350 \\
\hline 7 & 14561 & Lat48 & $1 \mathrm{~T}$ & 0.18 & 3.23 & 5 & 132 & 385 \\
\hline 8 & 17378 & Lat48 & $1 \mathrm{~T}$ & 0.16 & 3.61 & 5 & 148 & 429 \\
\hline 9 & 20368 & Lat48 & $1 \mathrm{~T}$ & 0.15 & 4.05 & 5 & 166 & 482 \\
\hline 10 & 11958 & Lat72 & $1 \mathrm{~T}$ & 0.28 & 4.24 & 8 & 173 & 504 \\
\hline 11 & 14561 & Lat72 & $1 \mathrm{~T}$ & 0.26 & 4.74 & 8 & 194 & 564 \\
\hline 12 & 17378 & Lat72 & $1 \mathrm{~T}$ & 0.24 & 5.37 & 7 & 220 & 638 \\
\hline 13 & 11958 & Lat96 & $1 \mathrm{~T}$ & 0.36 & 5.55 & 11 & 227 & 660 \\
\hline 14 & 14561 & Lat96 & $1 \mathrm{~T}$ & 0.34 & 6.30 & 10 & 258 & 749 \\
\hline 15 & 11958 & Lat120 & $1 \mathrm{~T}$ & 0.46 & 7.01 & 14 & 287 & 834 \\
\hline 16 & 11958 & Lat24 & $2 T$ & 0.11 & 1.24 & 3 & 51 & 148 \\
\hline 17 & 14561 & Lat24 & $2 \mathrm{~T}$ & 0.10 & 1.36 & 3 & 56 & 162 \\
\hline 18 & 17378 & Lat24 & $2 \mathrm{~T}$ & 0.10 & 1.49 & 3 & 61 & 178 \\
\hline
\end{tabular}


AIAA-2007-1101 - Lawrence L. Green

\begin{tabular}{|c|c|c|c|c|c|c|c|c|}
\hline 19 & 20368 & Lat24 & $2 \mathrm{~T}$ & 0.10 & 1.69 & 3 & 69 & 201 \\
\hline 20 & 11958 & Lat48 & $2 \mathrm{~T}$ & 0.24 & 2.76 & 7 & 113 & 328 \\
\hline 21 & 14561 & Lat48 & $2 \mathrm{~T}$ & 0.23 & 3.08 & 7 & 126 & 366 \\
\hline 22 & 17378 & Lat48 & $2 \mathrm{~T}$ & 0.23 & 3.44 & 7 & 141 & 409 \\
\hline 23 & 11958 & Lat72 & $2 \mathrm{~T}$ & 0.38 & 4.37 & 12 & 179 & 520 \\
\hline 24 & 14561 & Lat72 & $2 \mathrm{~T}$ & 0.37 & 4.93 & 11 & 202 & 587 \\
\hline 25 & 11958 & Lat96 & $2 \mathrm{~T}$ & 0.53 & 6.04 & 16 & 247 & 719 \\
\hline 26 & 11958 & Lat24 & $3 T$ & 0.13 & 1.35 & 4 & 55 & 161 \\
\hline 27 & 14561 & Lat24 & $3 T$ & 0.12 & 1.49 & 4 & 61 & 177 \\
\hline 28 & 17378 & Lat24 & $3 T$ & 0.12 & 1.69 & 4 & 69 & 201 \\
\hline 29 & 11958 & Lat48 & $3 T$ & 0.29 & 3.11 & 9 & 127 & 370 \\
\hline 30 & 14561 & Lat48 & $3 T$ & 0.28 & 3.48 & 9 & 142 & 413 \\
\hline 31 & 11958 & Lat72 & $3 \mathrm{~T}$ & 0.47 & 5.03 & 14 & 206 & 599 \\
\hline 32 & 11958 & Lat24 & $4 \mathrm{~T}$ & 0.16 & 1.53 & 5 & 63 & 182 \\
\hline 33 & 14561 & Lat24 & $4 \mathrm{~T}$ & 0.16 & 1.74 & 5 & 71 & 207 \\
\hline 34 & 11958 & Lat48 & $4 \mathrm{~T}$ & 0.36 & 3.57 & 11 & 146 & 424 \\
\hline 35 & 11958 & Lat24 & $3 X$ & 0.18 & 1.50 & 5 & 61 & 178 \\
\hline 36 & 14561 & Lat24 & $3 x$ & 0.16 & 1.61 & 5 & 66 & 192 \\
\hline 37 & 17378 & Lat24 & $3 X$ & 0.15 & 1.75 & 5 & 72 & 208 \\
\hline 38 & 20368 & Lat24 & $3 X$ & 0.15 & 1.93 & 5 & 79 & 230 \\
\hline 39 & 23490 & Lat24 & $3 X$ & 0.15 & 2.16 & 5 & 88 & 256 \\
\hline 40 & 11958 & Lat48 & $3 x$ & 0.34 & 2.84 & 10 & 116 & 337 \\
\hline 41 & 14561 & Lat48 & $3 x$ & 0.31 & 3.09 & 9 & 127 & 368 \\
\hline 42 & 17378 & Lat48 & $3 x$ & 0.30 & 3.44 & 9 & 141 & 409 \\
\hline 43 & 20368 & Lat48 & $3 x$ & 0.30 & 3.86 & 9 & 158 & 460 \\
\hline 44 & 11958 & Lat72 & $3 x$ & 0.49 & 4.07 & 15 & 167 & 484 \\
\hline 45 & 14561 & Lat72 & $3 X$ & 0.45 & 4.54 & 14 & 186 & 539 \\
\hline 46 & 17378 & Lat72 & $3 X$ & 0.44 & 5.13 & 13 & 210 & 610 \\
\hline 47 & 11958 & Lat96 & $3 X$ & 0.63 & 5.33 & 19 & 218 & 634 \\
\hline 48 & 14561 & Lat96 & $3 x$ & 0.61 & 6.04 & 18 & 247 & 719 \\
\hline 49 & 11958 & Lat120 & $3 x$ & 0.80 & 6.75 & 24 & 276 & 803 \\
\hline 50 & 11958 & Lat24 & $9 x$ & 2.55 & 1.36 & 77 & 56 & 162 \\
\hline 51 & 14561 & Lat24 & $9 x$ & 2.11 & 1.48 & 64 & 61 & 176 \\
\hline 52 & 17378 & Lat24 & $9 x$ & 1.86 & 1.63 & 56 & 67 & 194 \\
\hline 53 & 20368 & Lat24 & $9 x$ & 1.17 & 1.83 & 35 & 75 & 217 \\
\hline 54 & 23490 & Lat24 & $9 X$ & 1.02 & 2.06 & 31 & 84 & 245 \\
\hline 55 & 11958 & Lat48 & $9 X$ & 4.90 & 2.62 & 149 & 107 & 311 \\
\hline 56 & 14561 & Lat48 & $9 X$ & 4.13 & 2.90 & 125 & 119 & 345 \\
\hline 57 & 17378 & Lat48 & $9 x$ & 3.72 & 3.27 & 113 & 134 & 388 \\
\hline 58 & 20368 & Lat48 & $9 x$ & 2.38 & 3.72 & 72 & 152 & 442 \\
\hline 59 & 11958 & Lat72 & $9 x$ & 7.10 & 3.80 & 215 & 155 & 451 \\
\hline 60 & 14561 & Lat72 & $9 X$ & 6.14 & 4.31 & 186 & 176 & 512 \\
\hline 61 & 17378 & Lat72 & $9 x$ & 5.62 & 4.93 & 170 & 202 & 586 \\
\hline 62 & 11958 & Lat96 & $9 X$ & 9.40 & 5.03 & 285 & 206 & 598 \\
\hline 63 & 14561 & Lat96 & $9 x$ & 8.25 & 5.79 & 250 & 237 & 688 \\
\hline 64 & 11958 & Lat120 & $9 x$ & 12.03 & 6.43 & 365 & 263 & 765 \\
\hline
\end{tabular}


AIAA-2007-1101 - Lawrence L. Green

Table 9. Uncertainty Analysis for Track Error (1851-2004 Hurricanes)

\begin{tabular}{|c|c|c|c|c|c|c|c|c|}
\hline $\begin{array}{l}\text { Case } \\
\text { Index }\end{array}$ & $\begin{array}{l}\text { Number of } \\
\text { Data Points }\end{array}$ & Response & $\begin{array}{l}\text { Analysis } \\
\text { Type }\end{array}$ & $\begin{array}{c}\text { ANOVA } \\
\text { Model } \\
\text { Uncertainty } \\
\text { nm }\end{array}$ & $\begin{array}{l}\text { ANOVA } \\
50 \% \\
\text { Prediction } \\
\text { Error } \\
\mathrm{nm}\end{array}$ & $\begin{array}{l}\text { ANOVA } \\
95 \% \\
\text { Prediction } \\
\text { Error } \\
\mathrm{nm}\end{array}$ & $\begin{array}{l}\text { NHC } 50 \% \\
\text { Prediction } \\
\text { Error } \\
\text { nm }\end{array}$ & $\begin{array}{c}\text { NHC 95\% } \\
\text { Prediction } \\
\text { Error } \\
\mathrm{nm}\end{array}$ \\
\hline 1 & 11958 & Track24 & $1 \mathrm{~T}$ & 5 & 126 & 366 & 55 & 140 \\
\hline 2 & 14561 & Track24 & $1 \mathrm{~T}$ & 5 & 138 & 402 & 55 & 140 \\
\hline 3 & 17378 & Track24 & $1 \mathrm{~T}$ & 6 & 155 & 451 & 55 & 140 \\
\hline 4 & 20368 & Track24 & $1 \mathrm{~T}$ & 6 & 176 & 512 & 55 & 140 \\
\hline 5 & 23490 & Track24 & $1 \mathrm{~T}$ & 6 & 201 & 583 & 55 & 140 \\
\hline 6 & 11958 & Track48 & $1 \mathrm{~T}$ & 10 & 247 & 719 & 100 & 270 \\
\hline 7 & 14561 & Track48 & $1 \mathrm{~T}$ & 10 & 277 & 804 & 100 & 270 \\
\hline 8 & 17378 & Track48 & $1 \mathrm{~T}$ & 12 & 315 & 914 & 100 & 270 \\
\hline 9 & 20368 & Track48 & $1 \mathrm{~T}$ & 13 & 361 & 1049 & 100 & 270 \\
\hline 10 & 11958 & Track72 & $1 \mathrm{~T}$ & 14 & 370 & 1074 & 150 & 400 \\
\hline 11 & 14561 & Track72 & $1 \mathrm{~T}$ & 15 & 420 & 1220 & 150 & 400 \\
\hline 12 & 17378 & Track72 & $1 \mathrm{~T}$ & 19 & 483 & 1402 & 150 & 400 \\
\hline 13 & 11958 & Track96 & $1 \mathrm{~T}$ & 19 & 499 & 1450 & 195 & 630 \\
\hline 14 & 14561 & Track96 & $1 \mathrm{~T}$ & 21 & 573 & 1666 & 195 & 630 \\
\hline 15 & 11958 & Track120 & $1 \mathrm{~T}$ & 26 & 642 & 1865 & 260 & 700 \\
\hline 16 & 11958 & Track24 & $2 T$ & 5 & 83 & 242 & 55 & 140 \\
\hline 17 & 14561 & Track24 & $2 \mathrm{~T}$ & 5 & 92 & 268 & 55 & 140 \\
\hline 18 & 17378 & Track24 & $2 T$ & 5 & 103 & 300 & 55 & 140 \\
\hline 19 & 20368 & Track24 & $2 \mathrm{~T}$ & 5 & 116 & 337 & 55 & 140 \\
\hline 20 & 11958 & Track48 & $2 T$ & 13 & 198 & 577 & 100 & 270 \\
\hline 21 & 14561 & Track48 & $2 T$ & 13 & 223 & 648 & 100 & 270 \\
\hline 22 & 17378 & Track48 & $2 \mathrm{~T}$ & 13 & 252 & 733 & 100 & 270 \\
\hline 23 & 11958 & Track72 & $2 \mathrm{~T}$ & 22 & 332 & 966 & 150 & 400 \\
\hline 24 & 14561 & Track72 & $2 \mathrm{~T}$ & 22 & 378 & 1099 & 150 & 400 \\
\hline 25 & 11958 & Track96 & $2 T$ & 32 & 484 & 1406 & 195 & 630 \\
\hline 26 & 11958 & Track24 & $3 T$ & 6 & 91 & 263 & 55 & 140 \\
\hline 27 & 14561 & Track24 & $3 T$ & 6 & 102 & 296 & 55 & 140 \\
\hline 28 & 17378 & Track24 & $3 T$ & 6 & 114 & 331 & 55 & 140 \\
\hline 29 & 11958 & Track48 & $3 T$ & 16 & 224 & 650 & 100 & 270 \\
\hline 30 & 14561 & Track48 & $3 T$ & 16 & 253 & 735 & 100 & 270 \\
\hline 31 & 11958 & Track72 & $3 T$ & 27 & 384 & 1116 & 150 & 400 \\
\hline 32 & 11958 & Track24 & $4 \mathrm{~T}$ & 8 & 104 & 302 & 55 & 140 \\
\hline 33 & 14561 & Track24 & $4 \mathrm{~T}$ & 8 & 117 & 341 & 55 & 140 \\
\hline 34 & 11958 & Track48 & $4 T$ & 20 & 260 & 755 & 100 & 270 \\
\hline 35 & 11958 & Track24 & $3 x$ & 9 & 102 & 297 & 55 & 140 \\
\hline 36 & 14561 & Track24 & $3 x$ & 8 & 110 & 319 & 55 & 140 \\
\hline 37 & 17378 & Track24 & $3 x$ & 8 & 120 & 349 & 55 & 140 \\
\hline 38 & 20368 & Track24 & $3 x$ & 8 & 132 & 384 & 55 & 140 \\
\hline 39 & 23490 & Track24 & $3 x$ & 8 & 146 & 425 & 55 & 140 \\
\hline 40 & 11958 & Track48 & $3 x$ & 18 & 201 & 583 & 100 & 270 \\
\hline
\end{tabular}


AIAA-2007-1101 - Lawrence L. Green

\begin{tabular}{|c|c|c|c|c|c|c|c|c|}
\hline 41 & 14561 & Track48 & $3 x$ & 16 & 220 & 639 & 100 & 270 \\
\hline 42 & 17378 & Track48 & $3 x$ & 16 & 244 & 708 & 100 & 270 \\
\hline 43 & 20368 & Track48 & $3 x$ & 16 & 271 & 789 & 100 & 270 \\
\hline 44 & 11958 & Track72 & $3 X$ & 27 & 302 & 878 & 150 & 400 \\
\hline 45 & 14561 & Track72 & $3 x$ & 25 & 337 & 978 & 150 & 400 \\
\hline 46 & 17378 & Track72 & $3 x$ & 24 & 378 & 1098 & 150 & 400 \\
\hline 47 & 11958 & Track96 & $3 x$ & 36 & 413 & 1200 & 195 & 630 \\
\hline 48 & 14561 & Track96 & $3 x$ & 35 & 466 & 1355 & 195 & 630 \\
\hline 49 & 11958 & Track120 & $3 x$ & 48 & 539 & 1568 & 260 & 700 \\
\hline 50 & 11958 & Track24 & $9 x$ & 123 & 88 & 257 & 55 & 140 \\
\hline 51 & 14561 & Track24 & $9 x$ & 102 & 97 & 281 & 55 & 140 \\
\hline 52 & 17378 & Track24 & $9 x$ & 91 & 108 & 313 & 55 & 140 \\
\hline 53 & 20368 & Track24 & $9 x$ & 58 & 121 & 353 & 55 & 140 \\
\hline 54 & 23490 & Track24 & $9 x$ & 50 & 138 & 400 & 55 & 140 \\
\hline 55 & 11958 & Track48 & $9 x$ & 245 & 177 & 513 & 100 & 270 \\
\hline 56 & 14561 & Track48 & $9 x$ & 209 & 197 & 574 & 100 & 270 \\
\hline 57 & 17378 & Track48 & $9 x$ & 180 & 222 & 646 & 100 & 270 \\
\hline 58 & 20368 & Track48 & $9 x$ & 121 & 254 & 739 & 100 & 270 \\
\hline 59 & 11958 & Track72 & $9 x$ & 374 & 270 & 784 & 150 & 400 \\
\hline 60 & 14561 & Track72 & $9 x$ & 324 & 307 & 892 & 150 & 400 \\
\hline 61 & 17378 & Track72 & $9 x$ & 282 & 349 & 1014 & 150 & 400 \\
\hline 62 & 11958 & Track96 & $9 X$ & 519 & 374 & 1088 & 195 & 630 \\
\hline 63 & 14561 & Track96 & $9 x$ & 455 & 431 & 1252 & 195 & 630 \\
\hline 64 & 11958 & Track120 & $9 x$ & 687 & 496 & 1440 & 260 & 700 \\
\hline
\end{tabular}

Table 10. Uncertainty Analysis for Wind Speed (1851-2004 Hurricanes)

\begin{tabular}{|c|c|c|c|c|c|c|c|c|}
\hline $\begin{array}{l}\text { Case } \\
\text { Index }\end{array}$ & $\begin{array}{l}\text { Number of } \\
\text { Data Points }\end{array}$ & Response & $\begin{array}{c}\text { Analysis } \\
\text { Type }\end{array}$ & $\begin{array}{c}\text { ANOVA } \\
\text { Model } \\
\text { Uncertainty } \\
\text { kt }\end{array}$ & $\begin{array}{l}\text { ANOVA } \\
50 \% \\
\text { Prediction } \\
\text { Error } \\
\text { kt }\end{array}$ & $\begin{array}{l}\text { ANOVA } \\
95 \% \\
\text { Prediction } \\
\text { Error } \\
\text { kt }\end{array}$ & $\begin{array}{c}\text { NHC 50\% } \\
\text { Prediction } \\
\text { Error } \\
\text { kt }\end{array}$ & $\begin{array}{c}\text { NHC 95\% } \\
\text { Prediction } \\
\text { Error } \\
\text { kt }\end{array}$ \\
\hline 1 & 11958 & Wnd24 & $1 \mathrm{~T}$ & 0.41 & 9 & 26 & 10 & 30 \\
\hline 2 & 14561 & Wnd24 & $1 \mathrm{~T}$ & 0.37 & 9 & 27 & 10 & 30 \\
\hline 3 & 17378 & Wnd24 & $1 \mathrm{~T}$ & 0.34 & 10 & 28 & 10 & 30 \\
\hline 4 & 20368 & Wnd24 & $1 \mathrm{~T}$ & 0.33 & 10 & 30 & 10 & 30 \\
\hline 5 & 23490 & Wnd24 & $1 \mathrm{~T}$ & 0.33 & 11 & 32 & 10 & 30 \\
\hline 6 & 11958 & Wnd48 & $1 \mathrm{~T}$ & 0.61 & 14 & 40 & 10 & 40 \\
\hline 7 & 14561 & Wnd48 & $1 \mathrm{~T}$ & 0.55 & 14 & 41 & 10 & 40 \\
\hline 8 & 17378 & Wnd48 & $1 \mathrm{~T}$ & 0.51 & 14 & 42 & 10 & 40 \\
\hline 9 & 20368 & Wnd48 & $1 \mathrm{~T}$ & 0.49 & 15 & 44 & 10 & 40 \\
\hline 10 & 11958 & Wnd72 & $1 \mathrm{~T}$ & 0.72 & 16 & 47 & 15 & 50 \\
\hline 11 & 14561 & Wnd72 & $1 \mathrm{~T}$ & 0.64 & 16 & 48 & 15 & 50 \\
\hline 12 & 17378 & Wnd72 & $1 \mathrm{~T}$ & 0.60 & 17 & 49 & 15 & 50 \\
\hline 13 & 11958 & Wnd96 & $1 \mathrm{~T}$ & 0.77 & 17 & 50 & 15 & 60 \\
\hline 14 & 14561 & Wnd96 & $1 \mathrm{~T}$ & 0.70 & 18 & 52 & 15 & 60 \\
\hline 15 & 11958 & Wnd120 & $1 \mathrm{~T}$ & 0.48 & 18 & 53 & 15 & 60 \\
\hline 16 & 11958 & Wnd24 & $2 \mathrm{~T}$ & 0.44 & 9 & 26 & 10 & 30 \\
\hline
\end{tabular}


AIAA-2007-1101 - Lawrence L. Green

\begin{tabular}{|c|c|c|c|c|c|c|c|c|}
\hline 17 & 14561 & Wnd24 & $2 T$ & 0.39 & 9 & 27 & 10 & 30 \\
\hline 18 & 17378 & Wnd24 & $2 T$ & 0.37 & 10 & 28 & 10 & 30 \\
\hline 19 & 20368 & Wnd24 & $2 T$ & 0.36 & 10 & 30 & 10 & 30 \\
\hline 20 & 11958 & Wnd48 & $2 T$ & 0.66 & 14 & 40 & 10 & 40 \\
\hline 21 & 14561 & Wnd48 & $2 T$ & 0.59 & 14 & 41 & 10 & 40 \\
\hline 22 & 17378 & Wnd48 & $2 T$ & 0.56 & 15 & 42 & 10 & 40 \\
\hline 23 & 11958 & Wnd72 & $2 T$ & 0.78 & 16 & 47 & 15 & 50 \\
\hline 24 & 14561 & Wnd72 & $2 T$ & 0.70 & 17 & 48 & 15 & 50 \\
\hline 25 & 11958 & Wnd96 & $2 T$ & 0.85 & 18 & 51 & 15 & 60 \\
\hline 26 & 11958 & Wnd24 & $3 T$ & 0.49 & 9 & 27 & 10 & 30 \\
\hline 27 & 14561 & Wnd24 & $3 T$ & 0.44 & 10 & 28 & 10 & 30 \\
\hline 28 & 17378 & Wnd24 & 3T & 0.43 & 10 & 30 & 10 & 30 \\
\hline 29 & 11958 & Wnd48 & 3T & 0.72 & 14 & 41 & 10 & 40 \\
\hline 30 & 14561 & Wnd48 & $3 T$ & 0.66 & 15 & 42 & 10 & 40 \\
\hline 31 & 11958 & Wnd72 & 3T & 0.85 & 17 & 48 & 15 & 50 \\
\hline 32 & 11958 & Wnd24 & $4 T$ & 0.54 & 10 & 28 & 10 & 30 \\
\hline 33 & 14561 & Wnd24 & $4 T$ & 0.51 & 10 & 30 & 10 & 30 \\
\hline 34 & 11958 & Wnd48 & $4 T$ & 0.80 & 14 & 42 & 10 & 40 \\
\hline 35 & 11958 & Wnd24 & $3 X$ & 0.76 & 9 & 25 & 10 & 30 \\
\hline 36 & 14561 & Wnd24 & $3 x$ & 0.66 & 9 & 26 & 10 & 30 \\
\hline 37 & 17378 & Wnd24 & $3 x$ & 0.58 & 9 & 26 & 10 & 30 \\
\hline 38 & 20368 & Wnd24 & $3 x$ & 0.53 & 9 & 27 & 10 & 30 \\
\hline 39 & 23490 & Wnd24 & $3 x$ & 0.51 & 10 & 28 & 10 & 30 \\
\hline 40 & 11958 & Wnd48 & $3 x$ & 1.11 & 13 & 37 & 10 & 40 \\
\hline 41 & 14561 & Wnd48 & $3 x$ & 0.94 & 13 & 37 & 10 & 40 \\
\hline 42 & 17378 & Wnd48 & $3 X$ & 0.82 & 13 & 37 & 10 & 40 \\
\hline 43 & 20368 & Wnd48 & $3 X$ & 0.74 & 13 & 38 & 10 & 40 \\
\hline 44 & 11958 & Wnd72 & $3 x$ & 1.28 & 15 & 42 & 15 & 50 \\
\hline 45 & 14561 & Wnd72 & $3 x$ & 1.08 & 14 & 42 & 15 & 50 \\
\hline 46 & 17378 & Wnd72 & $3 x$ & 0.94 & 15 & 43 & 15 & 50 \\
\hline 47 & 11958 & Wnd96 & $3 x$ & 1.35 & 15 & 44 & 15 & 60 \\
\hline 48 & 14561 & Wnd96 & $3 x$ & 1.14 & 15 & 45 & 15 & 60 \\
\hline 49 & 11958 & Wnd120 & $3 X$ & 1.38 & 16 & 45 & 15 & 60 \\
\hline 50 & 11958 & Wnd24 & $9 X$ & 11.76 & 8 & 25 & 10 & 30 \\
\hline 51 & 14561 & Wnd24 & $9 x$ & 9.21 & 9 & 25 & 10 & 30 \\
\hline 52 & 17378 & Wnd24 & $9 x$ & 7.58 & 9 & 26 & 10 & 30 \\
\hline 53 & 20368 & Wnd24 & $9 x$ & 4.41 & 9 & 27 & 10 & 30 \\
\hline 54 & 23490 & Wnd24 & $9 X$ & 3.61 & 10 & 29 & 10 & 30 \\
\hline 55 & 11958 & Wnd48 & $9 X$ & 17.06 & 12 & 36 & 10 & 40 \\
\hline 56 & 14561 & Wnd48 & $9 X$ & 13.19 & 12 & 36 & 10 & 40 \\
\hline 57 & 17378 & Wnd48 & $9 X$ & 10.72 & 13 & 37 & 10 & 40 \\
\hline 58 & 20368 & Wnd48 & $9 x$ & 6.19 & 13 & 38 & 10 & 40 \\
\hline 59 & 11958 & Wnd72 & $9 x$ & 19.59 & 14 & 41 & 15 & 50 \\
\hline 60 & 14561 & Wnd72 & $9 x$ & 14.96 & 14 & 41 & 15 & 50 \\
\hline 61 & 17378 & Wnd72 & $9 x$ & 12.15 & 14 & 42 & 15 & 50 \\
\hline 62 & 11958 & Wnd96 & $9 x$ & 20.44 & 15 & 43 & 15 & 60 \\
\hline 63 & 14561 & Wnd96 & $9 x$ & 15.73 & 15 & 43 & 15 & 60 \\
\hline 64 & 11958 & Wnd120 & $9 X$ & 20.83 & 15 & 44 & 15 & 60 \\
\hline
\end{tabular}


Table 11. Prediction Validation Studies With 2005 Hurricanes

\begin{tabular}{|c|c|c|c|c|c|}
\hline $\begin{array}{l}\text { Validation } \\
\text { Set }\end{array}$ & $\begin{array}{l}\text { Validation } \\
\text { Case }\end{array}$ & $\begin{array}{l}\text { 24-Hour } \\
\text { Prediction }\end{array}$ & $\begin{array}{l}\text { 48-Hour } \\
\text { Prediction }\end{array}$ & $\begin{array}{l}\text { 72-Hour } \\
\text { Prediction }\end{array}$ & $\begin{array}{l}\text { 96-Hour } \\
\text { Prediction }\end{array}$ \\
\hline \multirow{2}{*}{$\begin{array}{l}\text { Hurricane } \\
\text { Emily }\end{array}$} & $\begin{array}{c}\text { ANOVA } \\
\text { Max Track } \\
\text { Error }\end{array}$ & 187 & 391 & 657 & 1043 \\
\hline & $\begin{array}{l}\text { ANOVA Avg } \\
\text { Track Error }\end{array}$ & 71 & 211 & 422 & 688 \\
\hline \multirow{2}{*}{$\begin{array}{l}\text { Hurricane } \\
\text { Katrina }\end{array}$} & $\begin{array}{l}\text { ANOVA } \\
\text { Max Track } \\
\text { Error }\end{array}$ & 243 & 559 & 850 & 1143 \\
\hline & $\begin{array}{l}\text { ANOVA Avg } \\
\text { Track Error }\end{array}$ & 120 & 291 & 454 & 572 \\
\hline \multirow{2}{*}{$\begin{array}{l}\text { Hurricane } \\
\text { Rita }\end{array}$} & $\begin{array}{l}\text { ANOVA } \\
\text { Max Track } \\
\text { Error }\end{array}$ & 207 & 453 & 716 & 1027 \\
\hline & $\begin{array}{l}\text { ANOVA Avg } \\
\text { Track Error }\end{array}$ & 69 & 189 & 332 & 453 \\
\hline \multirow{2}{*}{$\begin{array}{l}\text { Hurricane } \\
\text { Wilma }\end{array}$} & $\begin{array}{l}\text { ANOVA } \\
\text { Max Track } \\
\text { Error }\end{array}$ & 226 & 455 & 1153 & 1828 \\
\hline & $\begin{array}{l}\text { ANOVA Avg } \\
\text { Track Error }\end{array}$ & 50 & 126 & 147 & 106 \\
\hline \multirow{2}{*}{$\begin{array}{l}\text { All } 2005 \\
\text { Hurricanes }\end{array}$} & $\begin{array}{c}\text { ANOVA } \\
\text { 95\% Track } \\
\text { Error }\end{array}$ & 233 & 580 & 992 & 1458 \\
\hline & $\begin{array}{c}\text { ANOVA } \\
50 \% \text { Track } \\
\text { Error }\end{array}$ & 80 & 199 & 341 & 502 \\
\hline \multirow{2}{*}{$\begin{array}{c}\mathrm{NHC} \\
\text { Published } \\
\text { Accuracy }\end{array}$} & $\begin{array}{l}\text { 95\% Track } \\
\text { Error }\end{array}$ & 140 & 270 & 400 & 630 \\
\hline & $\begin{array}{l}50 \% \text { Track } \\
\text { Error }\end{array}$ & 55 & 100 & 150 & 195 \\
\hline
\end{tabular}

